University of New Mexico

UNM Digital Repository

Health, Exercise, and Sports Sciences ETDs

Education ETDs

12-7-1979

\title{
Maternal Compliance in Immunization of Pre-schoolers as Related to Health Locus of Control, Health Value, and Perceived Vulnerability
}

Estelle Helene Rosenblum

Follow this and additional works at: https://digitalrepository.unm.edu/educ_hess_etds

Part of the Health and Physical Education Commons

\section{Recommended Citation}

Rosenblum, Estelle Helene. "Maternal Compliance in Immunization of Pre-schoolers as Related to Health Locus of Control, Health Value, and Perceived Vulnerability." (1979). https://digitalrepository.unm.edu/ educ_hess_etds/113

This Dissertation is brought to you for free and open access by the Education ETDs at UNM Digital Repository. It has been accepted for inclusion in Health, Exercise, and Sports Sciences ETDs by an authorized administrator of UNM Digital Repository. For more information, please contact amywinter@unm.edu. 
3781

1564

R7245 
THE UNIVERSITY OF NEW MEXICO

\section{ALBUQUERQUE, NEW MEXICO 87131}

\section{Policy on Use of Theses and Dissertations}

Unpublished theses and dissertations accepted for master's and doctor's degrees and deposited in the University of New Mexico Library are open to the public for inspection and reference work. They are to be used only with due regard to the rights of the authors. The work of other authors should always be given full credit. Avoid quoting in amounts, over and beyond scholarly needs, such as might impair or destroy the property rights and financial benefits of another author.

To afford reasonable safeguards to authors, and consistent with the above principles, anyone quoting from theses and dissertations must observe the following conditions:

1. Direct quotations during the first two years after completion may be made only with the written permission of the author.

2. After a lapse of two years, theses and dissertations may be quoted without specific prior permission in works of original scholarship provided appropriate credit is given in the case of each quotation.

3. Quotations that are complete units in themselves (e.g., complete chapters or sections) in whatever form they may be reproduced and quotations of whatever length presented as primary material for their own sake (as in anthologies or books of readings) ALWAYS require consent of the authors.

4. The quoting author is responsible for determining "fair use" of material he uses.

This thesis/dissertation by Estelle Helene Rosenblum has been used by the following persons whose signatures attest their acceptance of the above conditions. (A library which borrows this thesis/dissertation for use by its patrons is expected to secure the signature of each user.)

NAME AND ADDRESS

DATE 
Estelle Helene Rosenblum

Candidate

Health, Physical Education and Recreation

Department

This dissertation is approved, and it is acceptable in quality and form for publication on microfilm:

Approved by the Dissertation Committee:

Elaine of. Stove ,Chairperson 11-30-79

But 9. Skipper

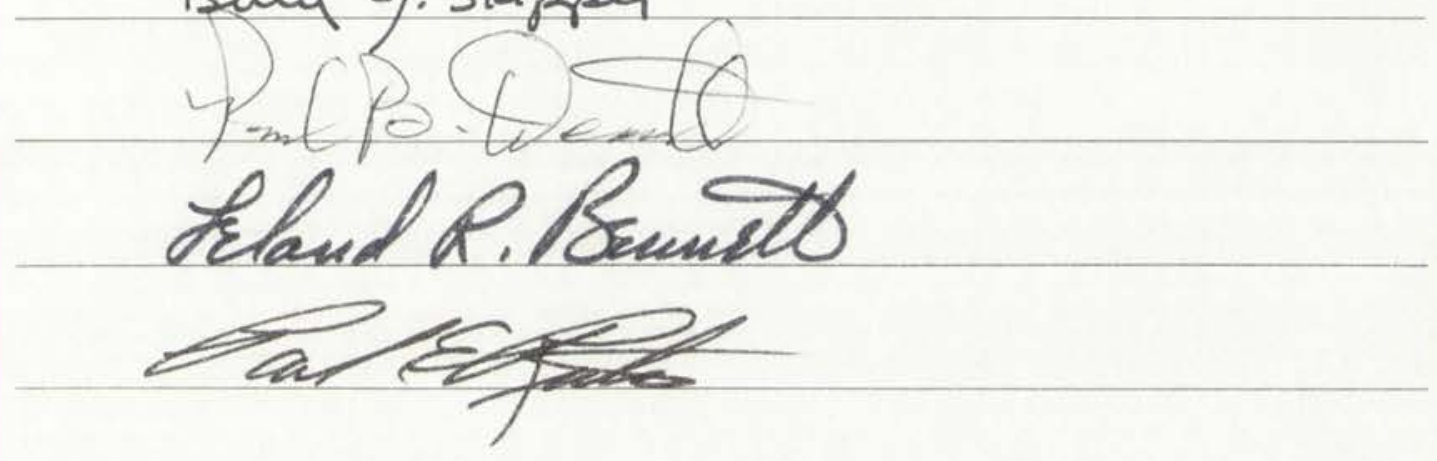

Accepted:

Charlene me hemet

Dean. Graduate School

reel, $\underset{\text { Date }}{1979}$ 

MATERNAL COMPLIANCE IN IMMUNIZATION OF PRE-SCHOOLERS AS RELATED TO HEALTH LOCUS OF CONTROL, HEALTH VALUE, AND

PERCEIVED VULNERABILITY

BY

ESTELLE HELENE ROSENBLUM

B.S.N., Wayne University, 1956

M.A., University of New Mexico, 1971

\section{DISSERTATION}

Submitted in Partial Fulfillment of the

Requirements for the Degree of

DOCTOR OF PHILOSOPHY IN EDUCATION

The University of New Mexico

Albuquerque, New Mexico

DECEMBER, 1979 
(C) Copyright by Estelle Helene Rosenblum, 1980 


\section{ACKNOWLEDGMENTS}

The author would like to express sincere appreciation to the following for their generous and constant support of this research study. To Dr. Elaine Stone, Chairperson, goes my deepest gratitude for offering continuous and tireless assistance from the conceptualization and distillation of the problem studied to the presentation of the proposal and the final dissertation manuscript. Dr. Betty Skipper was constantly available, patient, and instructive in all her generous assistance with data analysis and interpretation. Other committee members, Dr. Paul Dearth, Dr. Leland Bennett, and Dr. Paul Resta, were extremely supportive and constructive in both the design and methodology, and were generous with their donation of time and energy in reading and editing the manuscript.

I am grateful to the Rehabilitation Center of Albuquerque for permitting me to run the pilot study there, and to the Bernalillo County Office of Economic Opportunity Head Start staff, parents, and children for their cooperation in implementing this research study in their centers.

Dr. Jonathan Mann, Dr. Ann Pressman, Idol ia Collier, Kathy Chipman, Susan Timmons, Ruth Hunnicutt, Barbara Brennan, and Sally de Hon contributed much to individual tasks that resulted in the successful completion of this study.

To my typist, Lynn Rosner, who was always available, good 

natured, and competent, I am really indebted.

Finally, to my friends, who never stopped inquiring; to the faculty and staff who helped with real support; and to my loving family and husband, Sid, I express my deep appreciation for helping me to achieve one of my most valued life's goals. Thank you sincerely, 

MATERNAL COMPLIANCE IN IMMUNIZATION OF PRE-SCHOOLERS

AS RELATED TO HEALTH LOCUS OF CONTROL, HEALTH VALUE,

AND

PERCE I VED VULNERABILITY

BY

Estelle Helene Rosenblum

\author{
ABSTRACT OF DISSERTATION \\ Submitted in Partial Fulfillment of the \\ Requirements for the Degree of \\ DOCTOR OF PHILOSOPHY IN EDUCATION \\ The University of New Mexico \\ Albuquerque, New Mexico
}

DECEMBER, 1979 
MATERNAL COMPLIANCE IN IMMUNIZATION OF PRE-SCHOOLERS

AS RELATED TO HEALTH LOCUS OF CONTROL, HEALTH VALUE,

AND

PERCE IVED VULNERABILITY

Estelle Helene Rosenblum

Department of Health, Physical Education, and Recreation The University of New Mexico, 1979

The major purpose of this study was to assess health attitudes and behavior of mothers as related to providing immunizations for their pre-school children. The areas investigated were health locus of control, perceived vulnerability to six communicable diseases, health as a value, and the demographic variables of education, age, ethnicity, reigion, income, and ability to recall poliomyelitis.

This was a descriptive correlational study in which 95 mothers of children enrolled in Head Start Centers, Office of Economic Opportunity, Albuquerque, New Mexico, served as subjects. They were randomly selected from six centers serving multicultural neighborhoods in both urban and suburban areas. The mothers or subjects were divided into two groups based on whether or not they had met the criteria for compliance in providing complete immunizations for their pre-school children.

The data collection instruments used for testing subjects were the Multidimensional Health Locus of Control Instrument, the Demographic Data Collection Instrument, the Communicable Disease Perceived Vulnerability Instrument, and the Health Value Scale. 

The Communicable Disease Perceived VuInerability Scale was an original scale developed by the author for this study. Statistics used to analyze the data included descriptive statistics, analysis of variance, and chi-square analysis. The unit of measurement for the statistical analyses was each group's mean on the dependent variables.

The results indicated no statistically significant differences between compliant and non-compliant mothers on the basis of health locus of control, perceived vulnerability to the six diseases under study, or due to the demographic variables of education, age, ethnicity, religion, income, or the ability to recall the poliomyelitis epidemics of the 1950s. Most mothers selected health as a first or second choice from 10 values regardless of whether they had provided the required immunizations or not. Most mothers also reported perceived vulnerability to the six diseases, but it was not related to immunization compliance. Most of the mothers in this study could not recall the poliomyelitis epidemics of the 1950s nor had they been told about the disease by others. The large majority of subjects were Spanish-American, Catholic, in the ir late twenties, of low income, with high school or less education. 
TABLE OF CONTENTS

PAGE

LIST OF TABLES . . . . . . . . . . . . . . . . . $\times 1$

CHAPTER

1. THE PROBLEM AND RATIONALE ............. . . 1

Introduction ................... . . . 1

Statement of the Problem . . . . . . . . . 7

Major Problem .............. . 7

Secondary Problem ......... . . 7

Research Questions .. . . . . . . . 7

Hypotheses ............... 8

Delimitations............... . . . 9

Significance of the Problem......... . 9

Definition of Terms........... 13

11. REVIEW OF RELATED LITERATURE . . . . . . . . 16

The Health Bel ief Model and Related

Literature . . . . . . . . . . . . 16

Locus of Control Literature . . . . . . . . . 26

Health Locus of Control Literature . . . . . . 31

Immunization Practices and Preventive

Health Behavior.............. 38

Summary of the Review of Literature... . . . 52

111. METHODOLOGY ...................... 54

Subjects ................ . . 54

Instruments ................ . . 55

Design of the Study... . . . . . . . 62

Procedures ............... 63 
IV. ANALYSIS OF DATA ............. . . . 66

V. DISCUSSIONS, CONCLUSIONS, AND RECOMMENDATIONS . 87

Discussion............... . . 87

Conclusions . . . . . . . . . . . . . . 95

Recommendations for Future Research . . . . . 95

APPENDICES ......................... 98

Appendix A................ . 99

Appendix B..................... 101

Appendix C................ 103

Appendix D................ 105

Appendix E................. 110

Appendix F................ . . 112

Appendix G.................... $1 / 4$

Appendix H................ 116

Appendix 1................ . . 118

Appendix J................. 120

Appendix K.................... 123

REFERENCES ...................... 125 



\section{LIST OF TABLES}

TABLE

PAGE

1. Descriptive Statistics and Analysis of Variance Between Compliant and NonCompliant Groups on the Subscale of Internality............... .

2. Descriptive Statistics and Analysis of Variance on the Subscale of Chance for Compliant and Non-Compliant Groups and the Normative Data Group . . . . . . . . .

3. Comparison of Means on Subscale of

Chance with Original Multidimensional

Health Locus of Control Normative Data . . . .

4. Descriptive Statistics and Analysis of Variance on the Subscale of Powerful Others for Compliant and Non-Compliant Groups and the Normative Data Group . . . . .

5. Descriptive Statistics and Analysis of Variance of Compliant and Non-Compliant Groups in the Selection of Health as a Value.................

6. Perceived Vulnerability to Six

Communicable Diseases by Compliant and

Non-Compl iant Groups

7. Chi-Square Analysis of Compliant and Non-Compliant Mothers on the Basis of Education................

8. Chi-Square Analysis of Compliant and Non-Compliant Mothers on the Basis of

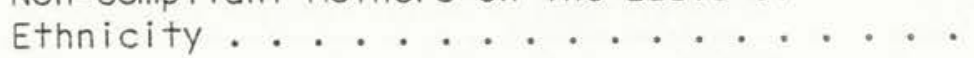

9. Chi-Square Analysis of Compliant and Non-Compliant Mothers on the Basis of Age...................

10. Descriptive Data on Income for Total Sample ................. 


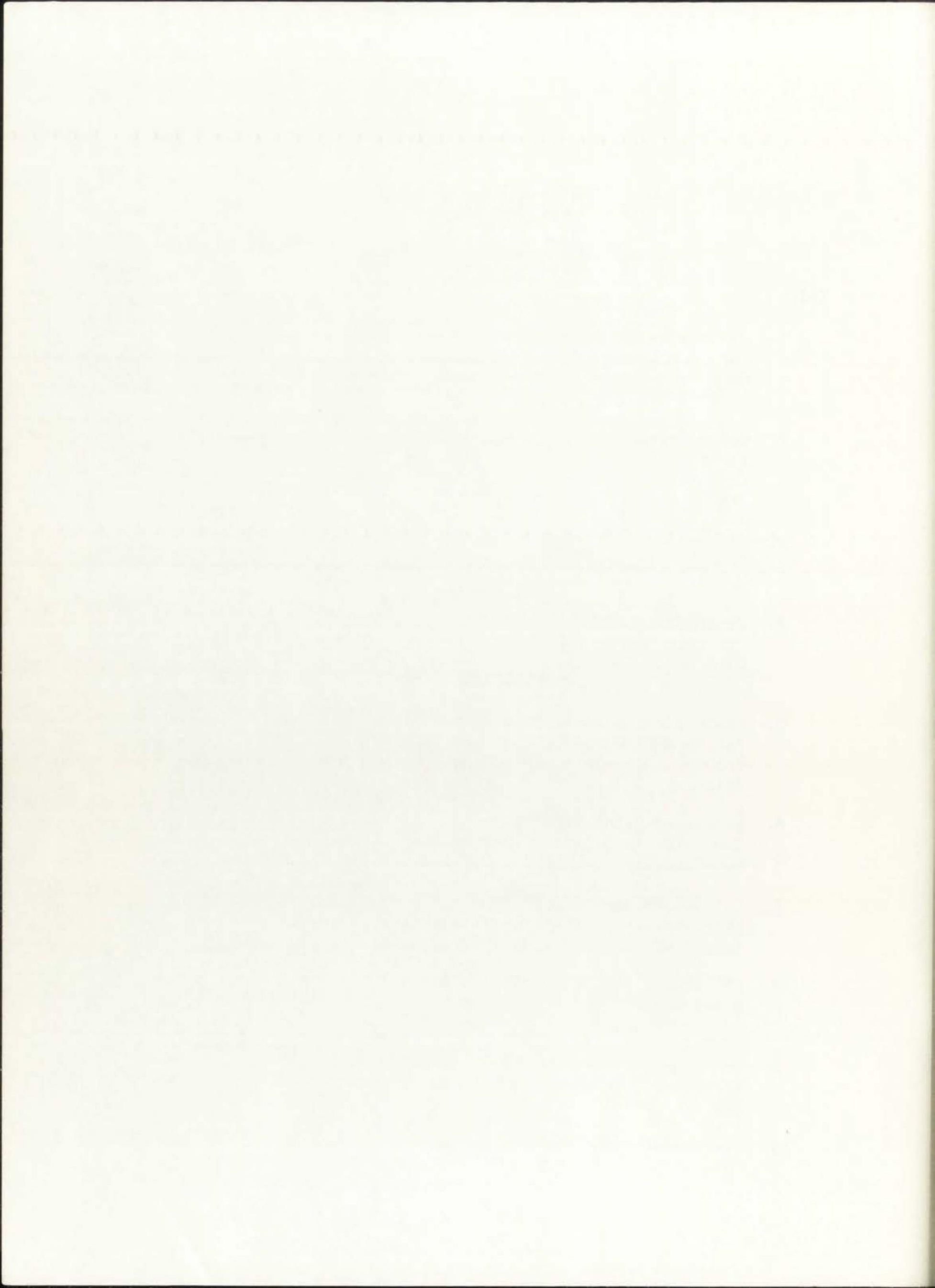


11. Descriptive Data on Religion for

Total Sample... . . . . . . . . .

12. Chi-Square Analysis of Compliant and Non-Compliant Mothers on the Basis of Recall of Poliomyelitis 



\section{CHAPTER ।}

\section{THE PROBLEM AND RATIONALE}

\section{Introduction}

Concern over the return of preventable childhood diseases in epidemic proportions has once again become a major public health problem. Reports of epidemics of poliomyelitis, measles, rubella, diphtheria, and pertussis in unprotected populations cause alarm on a national and international scale Center for Disease Control (CDC), Morbidity and Mortality Weekly Reports (MMWR), 26, 27, 28, 1978).

In 1976, 39,585 measles cases were reported; the largest number since 1971 (Bean, Burmeister, Paule, and Isacson, 1978). This is particularly distressing in face of large public health efforts to provide, without charge to any child, vaccine for diphtheria, pertussis, tetanus, poliomyelitis, and measles. In 1977, 55,201 cases of measles were reported. This was more than a $34 \%$ increase over the previous year as reported by the CDC (MMWR, $27(28), 1978)$.

On a national level, despite immunization programs throughout the country, the United States' annual incidence rate in 1977 


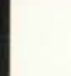
,

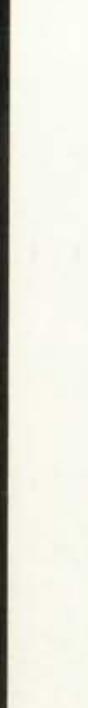

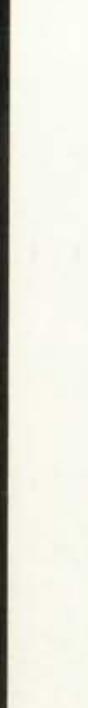

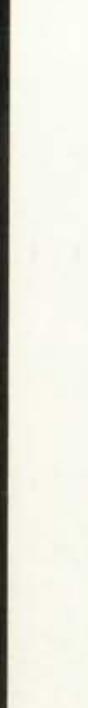

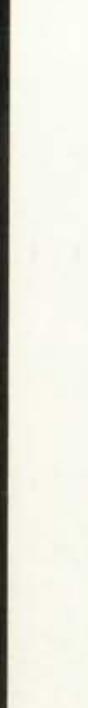

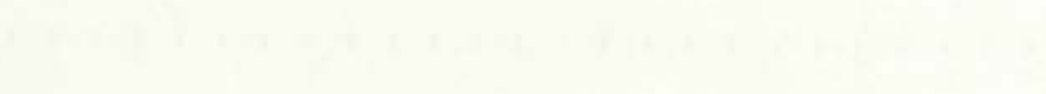

.
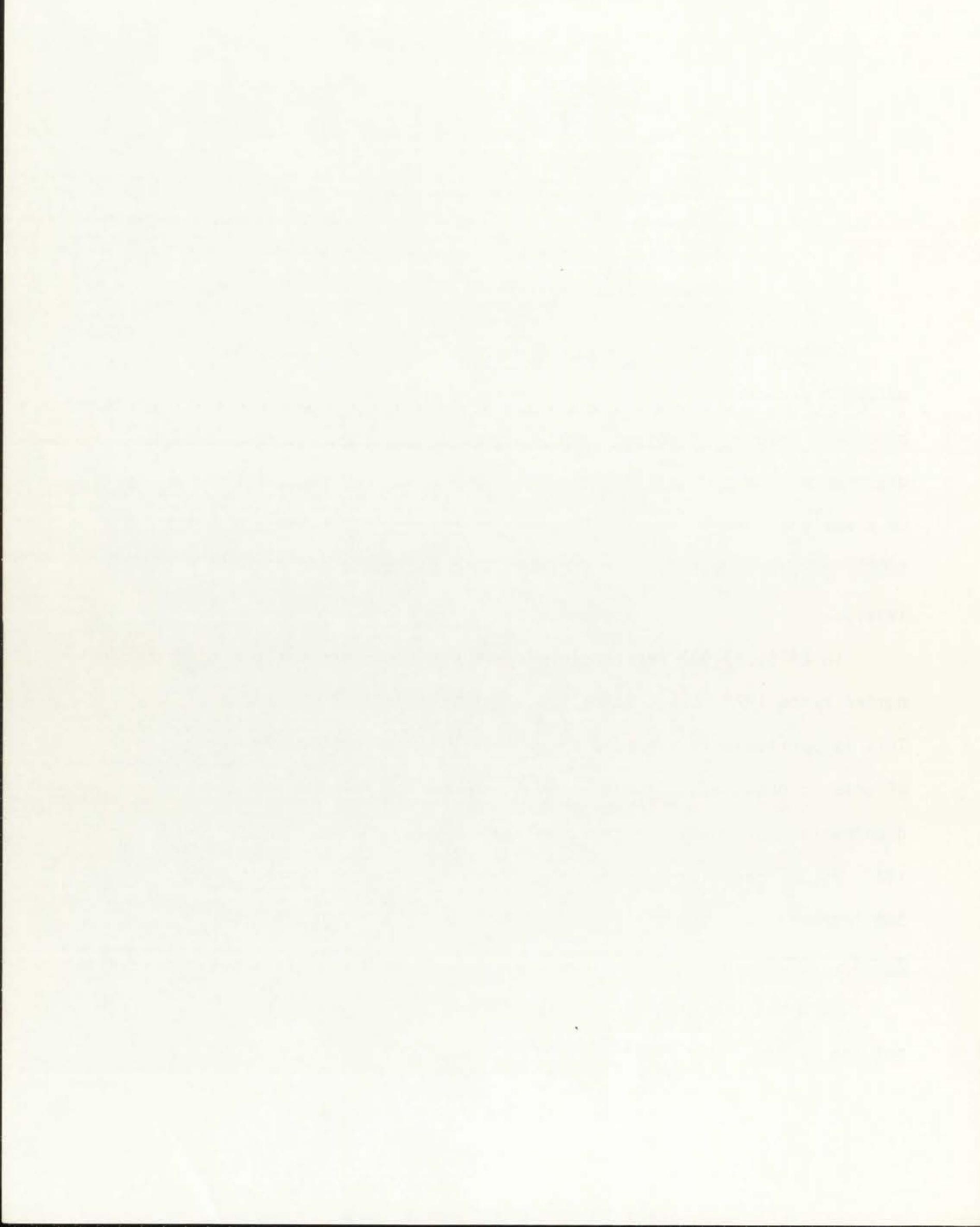
was 84.6 per 100,000 persons under 18 years of age. The highest rate occurred in lowa (496 per 100,000 population under 18) with Indiana, Minnesota, Montana, and New Hampshire showing rates more than twice the national average. In 1977 no state in the United States was reported to be free of measles (CDC, MMWR $\underline{27}(28)$, 1978). Current statistics from the Communicable Disease Center show that despite major health education and public health efforts there are still hundreds of children contracting diphtheria, a notoriousIy dangerous upper respiratory disease, as well as thousands contracting pertussis or whooping cough (CDC, MMWR $\underline{27}, \underline{28}, 1978$ ). Well over 100 cases of tetanus are seen annually, while measles and rubella lead the list of preventable diseases with nearly 25,000 to 50,000 cases reported annually in the United States (CDC, MMWR $27(39), 1978)$. In New Mexico, where this study was conducted, more than one-third of preschool children remain unprotected against preventable childhood diseases. According to Mann (1978), 35\% of all preschoolers in New Mexico are inadequately immunized against poliomyelitis. Another state survey (1978) indicated that 48,000 preschool children in New Mexico are not adequately immunized. Declining levels are not restricted to certain states or even confined to the United States. Bussey and Holmes (1977), reporting on declines in levels of immunization in England, noted that whooping cough protection was seriousiy lagging. The problems of declining levels of immunization protection in a vulnerable population are 
clearly a serious public health threat. It is essential to delineate factors that will motivate people to take certain positive health actions while relatively free of symptoms.

The myth that children invariably must get childhood diseases should be exposed as untrue and very risky. No longer considered expected childhood diseases, measles and rubella are responsible for sequella ranging from mild illness on one end of the health-illness continuum to serious neurological problems, including deafness, mental retardation, and blindness, on the other. Many children attending schools for the deaf were victims of the measles epidemics of the 1960s (Bassilli, 1976; Rosenblum, 1979; Northern and Downs, 1976). The reappearance of once dreaded diseases has caused government officials to organize on both the national and state levels. Governors' Committees, for example, have been formed to attack the apathy that leaves so many children and young adults unprotected from preventable diseases.

Preventive measures to eliminate certain childhood diseases have been available to the public for most of this century. Evidence that immunization is part of the foundation in a viable public health program has been demonstrated by the organized efforts in the United States and the international community to eradicate smallpox in the world by the 1970's. By organized and systematic immunization and surveillance programs, once dreaded diseases are no longer a major killer or maimer of children (Fox, 
Hall, and Elveback, 1970; Dowling, 1977; CDC, MMWR 26, 27, 28, 1978).

However, even with the offers of immunization services from the private and public sectors, there are still thousands of children who each year approach school entrance with incomplete or inadequate levels of immunization. Because mandatory state laws exist in most of the 50 states governing immunization practices, achieving adequate immunization levels is less a problem once a child reaches school age (Dowling, 1977). This is because school nurses, school administrators, official health departments, and private health care providers make attempts to notify parents of the state laws that require compliance to immunization regulations prior to school enroliment.

Since children, like two other groups in our society (the handicapped and the elder(y), are dependent on others for their health care, it is essential that we examine the factors that contribute to preventive health actions on the part of parents or the child's caretaker. Children and other dependent members of society must rely on others to arrange for both primary care and treatment when illness occurs. The success of their efforts rests on the attitudes, beliefs, and values held by the individual responsible for the care. Some parents may be influenced by a number of factors that operate either consciously or subconsciously to affect their health actions. 
Health behavior has been described as preventive behavior because it consists of actions taken for the purpose of maintaining or improving one's health and avoiding the effects of illness (Becker, 1966; Rosenstock, 1974). Rosenstock stressed that these actions are taken while the client is free of symptoms. This can be considered, then, as a salient feature of preventive health behavior.

The Health Belief Model, as first introduced by Hochbaum (1958) revealed that individuals engage in preventive health behavior based on several factors: perceived vulnerability, perceived severity, and perceived benefits (Becker, 1974; Gochman, 1972b; Kirscht, 1966; Rosenstock, 1974). Using immunization as an example, a person would have to believe that one was susceptible or vuinerable to one of these diseases in order to take the preventive action. An individual would also have to believe that the disease, if contracted, could be serious. Also, there would be the perception that obtaining the immunization would have real benefits in warding off the disease (Becker, 1974; Rosenstock, 1974).

Beliefs, attitudes, and values, as well as level of motivation, play a large role in health behavior. Recent studies by Wallston and Wallston (1976) and Saltzer (1978) focus on health locus of control as a variable affecting health care. Locus of control, a construct derived from Rotter's social learning theory 
(Rotter, 1966, 1971, 1972) described two opposite conceptual poles: internal control refers to the perception of events as being a consequence of a person's own actions and thereby under personal control; external control refers to the perceptions of events as being unrelated to a person's own behaviors in certain situations and therefore beyond personal control (Lefcourt, 1976; Rotter, 1966; Thornhill, 1975).

Whereas Rotter and other researchers discuss locus of control as a forced choice option which measures alternatives between internal and external control, Wallston and Wallston (1976) developed the construct more specifically to health. Recently a multidimensional scale of health locus of contro! was developed by Wallston and Wallston (1978) with norms obtained for several samples of adult populations (see Appendix A).

Given the significant increase in the rate of preventable childhood diseases cited earlier, attention must be focused on identifiable antecedent factors contributing to the problem. If the assumption is made that mothers as primary caretakers are responsible for insuring the health of their children, then an investigation of the attitudes and beliefs of this population in influencing compliance or non-compliance with recommended immunization programs is critical (Bullough, 1972; Wang, 1975). 



\section{Statement of the Problem}

\section{Major Problem}

The primary problem of interest in this research study was to investigate the relationship of health locus of control, the salience of health as a value, and perceived vulnerability of childhood diseases, as manifested by mothers of preschool children, with maternal compliance of recommended immunizations programs for their preschool children.

\section{Secondary Problem}

A secondary problem investigated in this study was the relationship of biographical variables, such as ethnicity, age, income, religion, level of education, and ability to recall such events as the poliomyelitis epidemics of the 1950s, and maternal compliance with recommended immunization schedules for their preschool children.

\section{Research Questions}

Research questions were developed as a basis for stating the hypotheses for this study. The research questions were as follows:

1. Will there be a difference in locus of control orientation between compliant and non-compliant mothers in regard to following guidelines for securing immunizations for their preschool children? 
2. Will there be a difference in compliance in immunization behavior for mothers who value health compared with mothers who do not value health?

3. Will there be a difference in compliance in immunization behavior for mothers who perceive their children to be susceptible or vulnerable to childhood diseases as compared with mothers who do not hold these beliefs?

4. Will ethnicity, income, religion, age, level of education, or ability to recall the poliomyelitis epidemics of the 1950 s be predictors of mothers obtaining required immunizations for preschool children?

\section{Hypotheses}

Based on previous research findings and theoretical concepts discussed in the review of literature, the following hypotheses were tested:

1. There will be a significant difference on locus of control orientation, as measured by the Multidimensional Health Locus of Control Scale (MHLC), between compliant and non-compliant mothers in regard to obtaining immunizations for their preschoolers.

2. There will be a significant difference on value of health, as measured by the Health Value Scale, between compliant and noncompliant mothers in regard to obtaining immunizations for their preschoolers. 
3. There will be a significant difference on perceived vulnerability, as measured by the Communicable Disease VuInerability Scale, between compliant and non-compliant mothers in regard to obtaining immunizations for their preschoolers.

4. There will be a significant difference between compliant and non-compliant mothers on the variables of education, income, religion, ethnicity, age, and ability to recall the poliomyelitis epidemics of the 1950s in relation to obtaining immunizations for preschoolers.

\section{Delimitations}

Subjects for this study were a sample of mothers of preschool children enrolled during 1979 in the Bernalillo County Office of Economic Opportunity's Head Start Program in New Mexico.

The instruments used in the study were as follows:

1. Demographic Data Collection Instrument (Appendix B)

2. The Health Value Scale (Appendix C)

3. The Multidimensional Health Locus of Control Scale (MHLC) (Appendix D)

4. The Communicable Disease Vulnerability Scale (Appendix E)

\section{Significance of the Problem}

The need to identify predictor variables in the area of com- 
pliance with immunization schedules in mothers of dependent preschool children is critical to the design of effective health education and immunization information programs. The present decline in immunization levels of this population and apathy in obtaining immunizations can result in the reappearance of epidemics of preventable communicable diseases. Knowledge of the variables that predict preventive health behavior can forward the goals of eventually eradicating childhood diseases from our society (Clausen, Seidenfeld and Deasy, 1954; Mechanic, 1964; Bussey and Holmes, 1977; Wan and Gray, 1978).

Previous research of parental attitudes showed that mothers who agreed to having their children receive poliomyelitis vaccinations did so because they believed that the vaccine would prevent poliomyelitis $(66 \%)$ or contribute to medical research (24\%). Among those refusing, $24 \%$ believed that the "shots were unsafe" (Clausen et al., 1954). Mechanic (1964) studied both parents and children in an exploratory study which compared the mother's educational level, fatalism and temperature taking when ill. The questions used in this study combined both locus of control orientation and perceived vulnerability to poliomyelitis. There have been many factors studied in the Health Belief Model (Becker, 1964; Becker, 1974; Campbel1, 1975; Clausen, 1944; Dodge, 1970; Glasser, 1958; Gochman, 1971 a and b, 1972; Guthrie, 1963; Rosenstock, 1974) in an attempt to identify the critical variables that result in respon- 

sible health action. The review of literature that follows

(Chapter 11) discusses in detail the major components of the Health Belief Model: perceived vulnerability, perceived severity, and, finally, perceived benefits (Hochbaum, 1958; Becker, 1974).

Becker (1974) discusses the research related to the question of whether perceptions of susceptibility, severity, benefits, and cost have a cut-off point. Is there a threshold level in terms of health action? If, as public health workers have recognized for years, there are different health beliefs for members of lower socio-economic status than there are for members of higher socioeconomic status, then how can these beliefs be quantified? There is much already known about health behavior in its most comprehensive sense. Steele and McBroom (1972) discuss health behavior as multidimensional, which means that people who engage in one behavior tend to engage in others.

Green (1970) believes that one of the major objectives of public health education is individual, voluntary, preventive health behavior. Green also states that public health education programs have shifted from emphasis on changing attitudes and providing information to providing social supports with an emphasis on group process. Since preventive health behavior is always action that is taken in the absence of symptoms, it is frequently measured by:

(1) earliness (reducing delay); (2) frequency (number of visits);

(3) persistence (receiving all inoculations) as well as a variety 
of other health actions. In this research, the variables of locus of control orientation as it affects health action will be studied as well as perceptions of the value of health and perceived vulnerability to the diseases in question.

If a person's locus of control orientation influences health action significantly, then future health education programs can be designed to utilize this predictor variable. Previous research (Chapter 11) discusses different programming for weight control based on locus of control orientation. Such information related to parents of preschoolers would be useful in designing effective health education programs in the immunization area.

The problem of declining levels of immunization is growing more alarming yearly. Newer strategies must be implemented to meet the needs of a younger population which lacks the fear of epidemics but has the responsibility for the health maintenance of the next generation.

Immunization or vaccination has long been regarded as an essential component in primary prevention. Such efforts as improved housing, environmental controls, adequate nutrition, recreation, and working conditions are part of the government's effort to prevent diseases from occurring. All of these efforts are important, but it is vaccination or immunization that has been described as putting a barrier between the agent and the host (Leavell, 1958). By preventing the disease from occurring in the first place, much waste in 
human suffering, job loss, and financial loss can be averted.

\section{Definition of Terms}

For purposes of this study the following definitions will be used:

Compliant: all immunizations under investigation have been given according to suggested guidelines or were delayed not later than two months with medical deferral.

Delayed-compliant: immunizations have been recorded as given, but were delayed more than two months.

Non-compliant: any one of the immunizations required was not given by 2 years of age, with no evidence of medical deferral. Health behavior: any activity undertaken by a person for the purpose of preventing disease or detecting disease in an asymptomatic state (KasI and Cobb, 1966).

Immunization: the act or process of rendering immune. For this study the term means receiving recommended vaccine for protection against the diseases of diphtheria, pertussis, tetanus, measles, rubella, and poliomyelitis (Fox, Hall, and Elveback, 1970). Immunization schedule: according to state laws mandating immunization practice, children who have reached their second birthday should have had the following immunizations (Mann, 1978):

-- diphtheria, tetanus, and pertussis (DPT) at 2,4 , and 6 months 
-- diphtheria, tetanus, and pertussis (DTP)

booster at 18 months

-- trivalent poliomyelitis at 2,4 , and 6 months

booster at 18 months

-- measles, rubella (mumps optional)

at 15 months

Basically, the three primary series of DPT and poliomyelitis are given before age 6 months. One year later, a booster of the same vaccine is given. Measles and rubella are given (sometimes with mumps) at age 15 months. Measles and rubel la had been given at age 12 months prior to 1978. Because this change in schedule might affect these subjects, either 15 months or 12 months will be accepted as compliance for purposes of this study (Appendix F). Locus of control: the extent to which a person perceives a relationship between his own behavior, and success or failure. If success or failure is perceived by the individual as being the result of chance, luck, fate, or under the control of powerful others, it is considered to be a belief in external locus of control. If success or failure is perceived by the individual as a result of the person's own behavior or one's own relatively permanent characteristics, it is considered to be a belief in internal locus of control (Rotter, 1966; Chance and Phares, 1972). Mothers: this will include biological mothers, caretakers, 

relatives or any person assuming responsibility for the child's health care.

Perceived vulnerability: this term means the same as perceived susceptibility, which refers to the subjective risks of being susceptible to contracting a health condition (Stone, 1976). Value: a belief upon which a person acts by preference. The term refers to what one feels one should do, ought to do, or must do whether or not one is consciously aware that these imperatives are giving direction to thoughts and actions (Knutson, 1974). 
CHAPTER II

\section{REV IEW OF RELATED LITERATURE}

The following four areas of literature were reviewed for this study:

1. The Health Belief Model and Related Literature

2. Locus of Control Literature

3. Health Locus of Control Literature

4. Immunization Practice and Preventive Health Behavior

\section{The Health Belief Model and Related Literature}

Health behavior that is consciously designed to either maintain already existing good health or to prevent disease from occurring has been the subject of continuous study by health educators, behavioral scientists, psychologists, and other medically oriented scientists. KasI and Cobb (1966) attempted to further define the terminology of health behavior, illness behavior, and sick role behavior. Their definitions for health behavior and illness behavior are as follows:

Health behavior was defined as an activity undertaken by a person who believes himself to be healthy for the purpose of preventing disease or detecting disease in an asymptomatic stage.

11 Iness behavior is defined as an activity undertaken by a person who feels ill, for the purpose of 

defining the state of his health and of discovering suitable remedy and the activity undertaken by those who consider themselves ill for the purpose of getting well (Kasl and Cobb, 1966, p. 246).

Many articles in the health education literature reflect on the dynamics involved in engaging in preventive health behavior that requires action or activity on the part of adults for both their own health or for their children for whom they assume the role of "health caretaker" (Rosenstock, Derryberry, and Carriger, 1959; Rosenstock, 1974; Suchman, 1965, 1967).

Rosenstock, Derryberry, and Carriger (1959) examined why people failed to seek polio immunization during the early critical years of the development of the Salk and Sabin vaccines. According to their findings, the decision to participate in a poliomyelitis vaccination campaign was influenced by two factors. One was personal readiness which consisted of an individual's perceptions of susceptibility and seriousness of the threat, and the second concerned situational factors such as personal convenience or effort required to get the vaccination. In another study, Rosenstock (1974) reports that the belief of not being susceptible to the disease was a factor that deterred adults from obtaining Asian Flu vaccine.

Moody (1972) studied nine demographic factors in an effort to determine which factors were predictors of preventive health behavior. The variable of education was reported as being the most impor- 

tant predictor, with income generally being a good predictor. Occupation had no great effect on preventive health behavior.

Social participation was identified as a variable for further investigation.

Health behavior may be described as preventive health behavior because it consists of utilization of health services for the assumed purpose of maintaining or improving one's health (Steele and McBroom, 1972). Rosenstock (1969) stresses the fact that health behaviors are those performed in an asymptomatic state. In his research, Rosenstock examined teethbrushing and obtaining chest $x$-rays as measures of preventive health behavior. Steele and McBroom (1972) in their study of health knowledge, beliefs, attitudes, and values, used four indicators of preventive health behavior: physical checkups, dental visits, eye doctor visits, and private insurance coverage. Their research identified distance to be travelled to a health facility as being a barrier to health care for those who have been recently ill.

Suchman (1965) examined the role of social group background (cosmopolitan versus parochialism and scientific versus popular approaches) as influences on health behavior. In his study of an ethnically mixed neighborhood in New York City, he found that low knowledge about disease and high skepticism of medical care as well as high dependence during ill ness seem to be related. Suchman found that individuals who belong to community groups which are 

highly exclusive ethnically as well as highly cohesive friendship groups and families oriented to tradition and authority are found to have a lower level of knowledge about disease, higher skepticism regarding medical care and greater dependency during il Iness. According to the National Health Survey as reported by Rosenstock (1974), the poor show substantially lower utilization than the non-poor in each of the following kinds of preventive and curative services: (1) percent under age 17 receiving physical exams; (2) percent under 17 visiting pediatricians; (3) percent of women visiting an obstetrician or gynecologist; (4) percent visiting dentist; (5) percent of women getting Pap smears; (6) percent of adults seeking regular chest $x$-rays; (7) percent obtaining poliomyelitis immunization; and lastly (8) percent brushing their teeth regularly. Despite government assistance in the area of health, studies indicate that the use of preventive services is related positively to income.

In general, past research has shown that more females than males visit physicians and dentists and incur hospitalization (excluding pregnancy). It also appears that the higher the socioeconomic status as measured by education and income, the higher the use of medical facilities, physicians, and dentists. When the fact of race is considered, more whites than non-whites utilize medical services, dentists, and hospitals. Persons who delay in seeking medical care are usually older, of low educational status, 

or males (Gordis, 1969; Green, 1970; Marston, 1970; Rosenstock, 1974).

In contrast, those who most frequently utilize services are white rather than black, younger or middle-aged people, females, as well as those with better education and higher incomes. An interesting finding related to this research was that even when immunizations are free, higher income families show a much better rate of participation than do poorer families (Campbell, 1975; Clausen et al., 1954; Coburn and Pope, 1974; Green, 1970; Rosenstock, 1974). Campbell (1975) believes that there is a double standard attributed to health: one person may see a runny nose as not signifying real illness while another equates a runny nose with a genuine need to seek help.

Two critical factors are identified by Campbell as playing a role in the seeking of medical care; the mother's occupation and the mother's educational status. Once again, there is replication of the finding that the higher the socio-economic level, the greater the health care sought. Kerrick, in a 1966 study of mothers in a maternity ward, found that the mothers who believed the illnesses to be most serious and their children most susceptible were the ones who knew the child's immunization status and had taken the responsibility for their children being fully immunized. Individual perceptions of health and illness that are influenced by modifying factors such as one's psychological state, social status, and cultural upbringing, will be important in how one en- 

gages in preventive health behavior cues to action such as mass media, advice from friends and family reminders, and print media; all play a role in influencing decisions about health activities. Hochbaum (1958), in a classic study of public participation in a medical screening program for tuberculosis, found that the two elements most predictive of preventive health behavior were perceived susceptibility and perceived benefits if preventive action were taken. Hochbaum's study was the original work in developing the Health Belief Model (Hochbaum, 1958; Becker, 1974). Additional findings of factors influencing preventive health behavior were psychological readiness, personal seriousness, a belief in the benefits of early diagnosis, and such situational factors as distance to be travelled to health facilities, other barriers to health care, and the preventing role of fear. What deters effective action, according to Hochbaum, is dislike for facing unpleasant possibilities, disregard for remote or future health treatments, and fear. Conflicting motives and health beliefs often result in the stronger motive governing health behavior (Hochbaum, 1958; Russell, 1975).

Kirscht (1972), in applying the Health Belief Model to illness behavior, states that there are four elements related to decisions to act given the presentation of symptoms (illness) plus the relationship of these elements to social structura! characteristics of the individual. They are: (1) health motiva- 

tion aroused by the symptoms; (2) the threat of the physical symptoms (physical harm); (3) the benefits of reducing the threat; and (4) barriers or costs of the action. Suchman (1965), in a study of Puerto Rico sugar cane accident prevention, found that workers who would accept a protective glove in order to el iminate machete cuts were demographically different from those who would not engage in this preventive health behavior. Those who would wear the protective gloves were younger, had fathers who were sugar cane cutters, were married, had higher incomes, and were literate. A further finding was that those who believe that accidents can be prevented wore gloves. Becker and Green (1975), in a family approach to compliance with medical treatment, identify three classes of individuals dependent on others for meeting their health needs. For the aging, the handicapped, and children, the perceptions and preventive health behavior of others will determine whether they get care, immunizations, or take medication when ill. This is particularly pertinent to this research study since infants and children are not the decision-makers in whether or not they will receive protective immunizations or vaccinations. Becker and Green (1975) studied what effects the family approach have on compliance of medical care. In a search of hundreds of articles the authors state that there is a disturbingly low rate of compliance to health or medical advice. There is agreement that less than one third of 
patient populations follow physicians' recommendations. As in personal health, the role of family in relation to children, aged, and disabled is a factor. The Health Bel ief Model in this case is the caretaker's subjective perception of the relative susceptibility of the dependent person, the perception of provable severity of the situation in question, and the potential benefits to be accrued if health action is taken.

Most of these studies have explored one or more elements of a health related psychological formulation called the Health Belief Model. The Model is derived from value expectancy models in which behavior is predicted from the value of an outcome to an individual and from the individual's expectations that a given action will result in that outcome (Becker and Green, 1975).

Rosenstock (1974) reports on the application and study of all elements of the Health Belief Model in a study of Tay-Sachs disease among Jews in the Boston-Washington area. In a population in which 1 in 900 is at risk, there is the opportunity for amniocentesis and the benefit of abortion if the diagnosis was made. Health motive was for the first time explicitly introduced into the Model to explain health behavior. In the Tay-Sachs study motive was a combination of desiring children and a set of generalized items about typical health behavior such as the frequency with which the person thinks about his own health and whether he visits a physician immediately when he thinks he is 111 . 

Perceived susceptibility included the person's belief that he could carry the Tay-Sachs gene and transmit it to his progeny. Severity was interpreted as the individual's views of the potential impact of learning that he was a carrier, while perceived benefits regarded one's views regarding the outcome (Rosenstock, 1974).

Markland, Durand, and Douglas (1976) reported on a questionnaire survey of the parents of two year olds regarding immunization status. Using at-home interviews and an interview format, the following findings were reported:

\section{Adequately Immunized}

1. High perception of disease seriolisness

2. High perception of risk of disease

3. Adequate knowledge of efficacy of vaccine

4. Adequate knowledge of length of protection afforded by vaccine

5. Higher age levels in parents

6. Higher educational levels in parents

7. Smaller families

8. Greater media exposure

9. Greater proportion of white children

\section{Inadequately Immunized}

1. Low perception of disease seriousness

2. Low perception of risk of disease

3. Inadequate knowledge of efficacy of disease 

4. Inadequate knowledge of length of protection afforded by vaccine

5. Lower age levels in parents

6. Lower educational levels in parents

7. Larger families

8. Lesser media exposure

9. Lesser proportion of white children.

These two profiles support earlier reported studies that adequately immunized infants tended to be found in families whose parents were more aware of disease seriousness, risk, and vaccine efficacy. Moreover, infants of young, poor, and less educated parents tended to be inadequately immunized. Additionally, nonwhites and large families were associated with inadequate immunization. The authors note that these findings are hardly new to the experienced public health worker. The development of discriminant analysis based on geographical areas shows great promise for defining future programming in immunization.

By having the capability to 'discriminate' (select) inadequately immunized infants from those with adequate protection using only socio-demographic data, innovative immunization programs may be instituted. As an example, it was noted above that low income and large family size contributed to low immunization. By using this discriminant function as an 'early warning' system, an individualized calendar for a newborn which indicates needed immunizations could be computer generated and mailed to parents of infants who are not likely to obtain proper inocuiations (Markland et al., 1976, p. 169). 



\section{Locus of Control Literature}

This study examined some of the relationships between health locus of control and one component of preventive health behavior: securing a series of immunizations for a dependent child. Health locus of control, a relatively new concept, has evolved from a more general psychological construct, locus of control. The review of Iiterature for this section will be divided into three parts: (1) an overview of the construct of locus of control; (2) a discussion of the newer or more recent concept of health locus of control; and (3) a concluding section summarizing the present state of knowledge of this concept.

\section{Overview of Locus of Control}

The concept of locus of control in its most basic form generated from the social learning theory of Rotter (1954) which states that:

. . the potential of a given behavior (or set of behaviors) occurring in a specific situation is a function of an individual's expectation that the behavior(s) will lead to a particular reinforcement available in that situation and the value of that reinforcement to the individual (Rotter, 1966, p. 1). Rotter developed the social learning theory to a concept of a dichotomous scale ranging from a totally external orientation to an internal orientation of control over one's destiny. Rotter stated:

When a reinforcement is perceived by the subject 
as following some action of his own but not being entirely contingent upon his action, then, in our culture, it is typically perceived as a result of luck, chance, fate, or under the control of powerful ohters, or as unpredictable because of the great complexity of the forces surrounding him. When the event is interpreted in this way by an individual, we have labeled this a belief in external control. If the person perceives that the event is contingent upon his own behavior or his relatively permanent characteristics, we have termed this a belief in internal control (Rotter, 1966, p. 1).

In Rotter's theory, a person's actions are predicted on the basis of his values, his expectations, and the situations in which he finds himself. "The formulation for predicting behavior at a specific time and place is as follows:

$$
B P \times, S 1, R a=f(E x, R a, S 1 \& R V a, S 1) .
$$

The formula reads: the potential for behavior $x$ to occur in situation 1 , in relation to reinforcement a, is a function of the expectancy of the occurrence of reinforcement a following behavior $x$ in situation 1, and the value of reinforcement a in situation 1. Conceptually, according to Lefcourt this formula demonstrates that the importance of expectancies is not secondary to values. It is this equal emphasis upon value, expectancy of reinforcement, and situational specificity that makes Rotter's theory so unique among other learning theories" (Lefcourt, 1976, p. 26).

Rotter viewed these generalized expectancies regarding the nature of the causal relationship between one's own behavior and 

its consequences as a major force in a person's response to different situations. According to Stone, an expectancy is a product of an individual's history of reinforcement, which is affected in turn by race, social status, and other variables (1976).

Originally the idea of internal and external locus of control emerged as a result of how people responded to chance or risk. Situations in which behavior event contingencies were governed by the subject's skill led to different performance than did situations in which such contingencies were random. Phares (1957) demonstrated that outcomes differed depending on whether the subjects were told that success on a task was governed by skill or by chance. Phares first attempted to measure this concept of locus of control by use of a Likert scale format. The instrument was composed of 13 skill items and 13 chance items. Lefcourt (1976) followed up Phares' work with improvements of the original scale.

Julius Rotter, an experimental psychologist at the University of Ohio, expanded the scale into a 29 item forced choice procedure which was designed to measure differences in locus of control. The Rotter Internal-External Scale is well-known and has been the forerunner of the following scales:
Name of Scale
Author
Year
Bialer's Locus of Control Questionnaire
Bialer
1961 
Name of Scale

Crandall Intellectual Achievement Responsibility Questionnaire

Dean's Alienation Scales

James I-E Scale

Nowicki-Strickland Locus of

Control Scale

Reid-Ware Three Factor I-E Scale

Rotter's I-E Scale

Stanford Pre-School I-E Scale

Interview questions for assessing

values, expectancies, and locus

of contro!
Author

Year

Crandall,

1965

Katkovsky,

and CrandalI

Dean

1969

James

1957

Nowicki and

Strickland

Reid and Ware

1974

Rotter

1966

Mischel, Zeiss, and Zeiss

Lefcourt, Reid, and Ware

(Lefcourt, 1976, pp. 157-187).

The Rotter Internal-External Scale has been used extensively with adults, is multidimensional, and contains items from the following areas: academic recognition, love and affection, dominance, social-political events, and general life philosophy.

\section{Studies of Locus of Control}

The focus of this study was on the more recent health locus of control instrument which will be discussed in the next section. However, a summary of the state of research in the general topic 
is important at this point.

Researchers attempted early to study what it is that distinguishes those with an internal orientation from those with an external orientation in terms of how one copes in attaining mastery over his environment. The research seems to demonstrate that those who seem most internally controlled probably have superior cognitive processing ability, seek more information in problem solving, and have better skills at actually utilizing and processing information (Lefcourt, 1976). According to Phares (1976), internals pay more attention to relevant cues in any situation.

Lefcourt believes that control is positively associated with access to opportunity. He states that:

. those who are able, through position and group
membership, to attain more readily the valued out-
comes that allow a person to feel personal satis-
faction are more likely to hold internal control
expectancies. Blacks, Spanish-Americans, Indians,
and other minority groups who do not enjoy as much
access to opportunity as do the predominant
caucasian groups in North American society are
found to hold fatalistic, external control beliefs
(Lefcourt, 1976, p. 25).

Individuals shown to have internal versus external attitudes on the I-E Locus of Control Scale or related instruments differ in a number of ways. According to Aarons (Lefcourt, 1976), those who tend to believe in internal control have been shown to be more resistant to subtle attempts to influence them and manifest less of a need to conform in social situations as well. In a study 
examining locus of control and general fearfulness in retirees, it was found that internals participated less in social activity than externals. The authors concluded that internals may resist pressure to conform and to participate in planned activities and have less of a need to engage in social activities, preferring sol itary activities (Brodie, 1977).

\section{Health Locus of Control Literature}

From the original construct of internal versus external control posited by Julius Rotter in the fifties has developed a considerable research interest in the relationship of this construct and health-related behaviors (Wallston and Wallston, 1978a; Kaplan, and Maides, 1976; Wallston and Wallston, 1978b). This section will review the current state of the literature as it relates to locus of control and then to health specifically.

Waliston and Wallston (1978a) reviewed the current literature on health behavior and sick role behavior, and locus of control. They indicate that published research on illness behavior and locus of control was not available. This review of the literature covers the areas of smoking, birth control, weight loss, and other preventive health topics. One of these literature reviews deals with inoculation and classifies influenza vaccine as preventive health behavior. This review will summarize the findings of Wallston and Wallston's review of Iiterature and 
also other current research in health locus of control and preventive health behavior in obtaining vaccination.

\section{$\underline{\text { Smoking }}$}

According to the Wallston review (1978a, p. 118) some stuies have shown "that internals (those who bel ieve that reinforcement is contingent upon the individual's behavior) are more likely to engage in behaviors that facilitate physical well-being." In studies by James, Straits, and Sechrest, non-smokers were more likely to be internal than smokers. Males who bel ieved the Surgeon General's Report and actually quit smoking were more internal than those who believed the report but did not quit smoking. Strickland further stated that internals were able to change smoking behavior to a greater extent than were externals (those who bel ieve reinforcement is controlled by outside forces such as fate, luck, chance, or powerful others) (1976). In other reported studies, internals were more likely to reduce their smoking. Studies reported that do not corroborate relationships between locus of control and smoking have been reported by Best and Stuffy, and Lichtenstein and Keutzer (WalIston and Wallston, 1978a). These studies reported in 1971 and 1967, respectively, used the earlier internal-external locus of control scales.

\section{Birth Control}

Research by Lundy (1962) has shown that among single female 


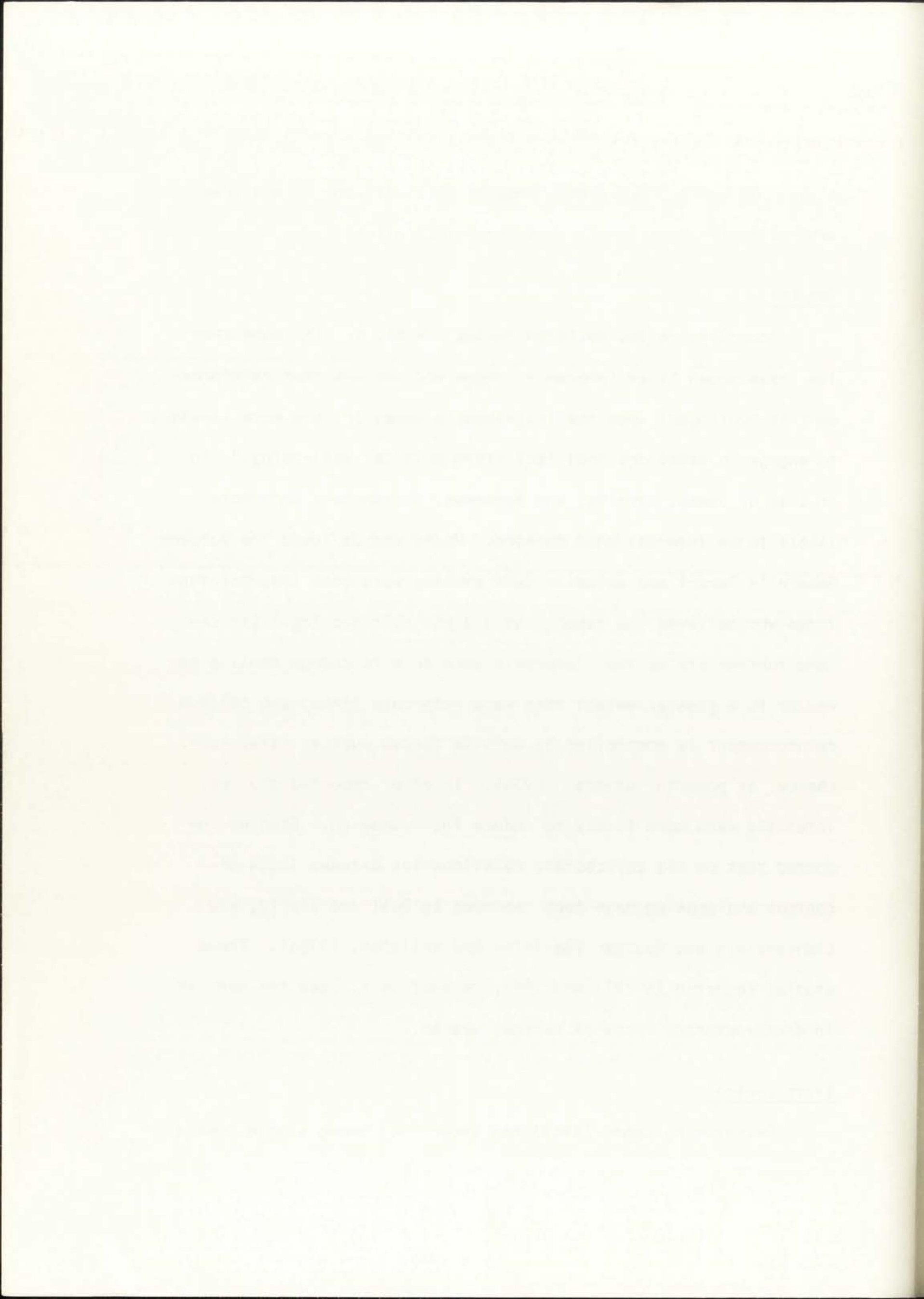


college students, $62 \%$ of the internals practiced contraception while only $37 \%$ of the externals did so. He also found that sexually active contraceptive users were more internal than sexually active nonusers. However, in a study by Phares (1976), locus of control was not related to the use of contraceptives in girls who were sexually active. Other research on the Health Locus of Control Scale (HLC) for unwed mothers and abortion patients, indicated that both groups scored slightly more internal than female norms. Wallston and Wallston (1978d), who are in personal communication with researchers utilizing the recent health locus of control scales, report that there is no relationship shown in recent research on locus of control and contraceptive use.

In a study examining internal versus external ego orientation and family planning effectiveness among poor black women, no significant differences in locus of control were noted. Generally speaking, powerlessness, a concept similar to locus of control, was found in one study (Wallston and Wallston, 1978a) to be a relatively strong predictor of failure to regularly practice contraception among a sample of black, married, recent fathers. Keller (1970) reports that contraceptive users were more likely to have high feelings of efficacy than nonusers.

\section{Weight Loss}

Weight loss (actively engaging in behavior that reduces 
weight) has been the subject of numerous studies. In this area locus of control seems to be a relevant factor. This is an interesting related area of research since health education programs may prove to be less effective if the locus of control orientation of subjects is not used in their initial design. In a study that examined negative covert reinforcement with positive covert reinforcement, it was found that externally oriented subjects who weighed more initially lost less weight while those with an internal orientation were more successful at weight loss (Manno and Marston, 1972). In a study by Balch and Ross (Wal Iston and Wallston, 1978a) in which the median weight loss was eight pounds, a relationship between success and self-control was demonstrated, once again indicating that treatment plans may be differentially effective for internals and externals. The Wallston review of a study by O'Bryan reports that overweight women enrolled in a TOPS (Take Off Pounds Sensibly) program were found to be more external than internal. Thus, while some studies do not show a significant weight loss by use of either the 1-E Scale or the HLC Scale, there is a difference shown on the placement of subjects in groups.

Based on the limited research in the area of health locus of control and weight reduction, the Wallstons suggest that:

. . internals be enrolled in more independent, selfregulated reduction programs while externals would profit more from programs that rely on prestige 

suggestion or support from others (Wallston and Wallston, 1978a, p. (11).

\section{Vaccination Behavior and Health Locus of Control}

In a study of college students who volunteered to receive influenza vaccine, the authors (Dabbs and Kirscht, 1971) studied locus of control and preventive health behavior. There are listed in the references many related studies that examine perceived vulnerability or susceptibility, but none that report on health locus of control and immunization behavior. The Wallstons (personal correspondence, 1978d) have listings of researchers conducting studies in the area of health locus of control. Studies under current investigation or in the planning stages include the following topics: psychosocial care of cancer patients, student health, health status of clerical workers, health education programs, chronic lung disease, smoking cessation, cardiac programs, arthritis, diabetes, hypertension, navy personnel, weight control, post-surgical progress, health promotion, control of pain, chronic renal failure, dental care, parents of asthmatic children, migrant farm workers, veterans' hospital patients, death education, different cultures, swimmers, first-time patients, epilepsy, alcoholism, family systems beliefs, biofeedback, worried well, characteristics of women who choose home births, medication compliance, and users of neighborhood health centers. Since the Dabbs and Kirscht research examines the relationship of locus of control and preventive health behavior in the form of obtaining immunizations, it 
will be discussed in detail (Dabbs and Kirscht, 1971).

Expectancies about ability to control the environment and motivation to exert control were assessed. among 510 college students in Michigan, half of whom had voluntarily taken influenza inoculations. The researchers based their hypotheses on the premise that individuals who believe that they can control their environments often try to do so. In the medical area, for example, patients with greater feelings of internal control appear to ask more questions and find out more about their illness (Wallston and Wallston, 1978). Research also indicates that a person's belief that he can exert control may be empirically related to his actual behavior (Dabbs and Kirscht, 1971).

It was Rotter who differentiated between expectancy variables and motivational variables (Rotter, 1966). The following items from his scale serve to illustrate these distinctions: Expectancy items

In most situations a person can control what happens. A person can avoid illness if he really tries.

\section{Motivation items}

I try to overcome bad luck. I really try to avoid illness. When the two are combined

People do what they can to control what happens.

The Dabbs-Kirscht study consisted of mailing a questionnaire to over 300 University of Michigan students who had taken influenza 
shots within the last 3 months and to a control group of 390 who had not. With an $87 \%$ return from the treatment group and an $82 \%$ return from the control group, the researchers found that high motivation to exert control was associated with taking shots; high expectancy of control was associated with not taking shots. The negative relationship between expectancy and inoculation is consistent with the idea that expecting control can lead to a feeling of invulnerability and a resulting lack of concern.

Using a seven point Likert scale the researchers used three questionnaire items reflecting vulnerability. Subjects were asked if they were the kind of person who could catch flu easily; if they caught flu, would it be serious; and if they were concerned about catching flu.

This overall vulnerability score was correlated positively with subjects' motivation to exert control. Subjects seemed to feel less vulnerable when they expected to be able to exert control. The measure of vulnerability was positively related to obtaining a shot. The Dabbs-Kirscht research is important to the present research for two reasons. One, it reflects two distinct psychological processes: motivation and expectancy. Motivation may lead to a person protecting himself and expectancy may lead him to neglect protection. Secondly, it relates well to the body of research on perceived vulnerability discussed earlier in this review of the literature. 
Immunization Practices and Preventive Health Behavior

There is considerable literature on immunization, immunology, and the morbidity due to infection. This review shall concern itself with the following related topics.

1. Background of immunization

2. Morbidity and mortality statistics of the diseases being investigated: poliomyelitis, measles (rubeola), rubella, diphtheria, pertussis (whooping cough), and tetanus

3. Current recommendations of the Public Health Service and the Advisory Committee of the American Pediatric Association (see Appendix F)

4. Summary of current Iiterature on behavior related to obtaining immunizations, health locus of control, and the health belief model as it relates to mothers of dependent children.

\section{Background of Immunization}

The history of infectious disease throughout the ages is replete with the recorded history of the ignorance and fear that finally gave way to a more progressive and scientific approach in the nineteenth and twentieth centuries. Progress from reliance strictly on symptomatic control and quarantine shifted dramatically with the discovery of the microscope and the subsequent utilization of microbiology to distinguish one organism from another.

Major progress began with the courageous experimentation of 
such early scientists as Henle, Koch, and Davaine. Concepts such as "before a living agent could be considered the cause of a disease, it would have to be identified, grown apart from other agents, and then used to produce the disease it was supposed to cause" emerged with each succeeding experiment (Dowling, 1977, p. 42. Inoculating healthy animals with blood from diseased ones led to the investigations that resulted in clear evidence that some bacteria produce disease and can be isolated in pure culture.

At the end of the eighteenth century, Edward Jenner validated a belief prevalent among rural people in parts of England that human infection with cowpox induced resistance to smallpox. His scientific experiment initiated one of the most successful preventive measures of all time. Jenner is credited with a rabies control program instituted in Scandinavia that rid the entire area of that "justly feared disease" by 1925 (Fox et al., 1970, p. 2).

Snow, an English anesthesiologist, is credited with a carefully controlled series of field observations and studies that led to recommendations that controlled the transmission of cholera (Dowling, 1977). Further research led to the germ theory. Putting the germ theory to work was the contribution of Louis Pasteur in 1880. Pasteur found that the bacillus of chicken cholera lost much of its virulence when kept for some time and that the injection of weakened or attenuated bacilli protected fowls against subsequent infections of virulent bacilli. Pasteur also 

experimented with the use of progressively increasing doses of attenuated vaccines which would cause immunity in the host but not a virulent form of the disease. "This principle of weakening or attenuating the vaccine is the basis for all immunizations programs that were to follow" (Dowling, 1977, p. 5).

Following Pasteur, Joseph Lister began in 1865 to search for a chemical compound to help prevent the infection and mortality of surgical incisions on wounds. His search led to Phenol (actually carbolic acid) which was tested empirically in the clinical area with dramatic results. In the 1880 s another technique called "asepsis" was introduced which consisted of sterilizing all objects coming in contact with a wound rather than kiliing microorganisms with chemical compounds. Asepsis finally replaced antisepsis because it was "just as effective and much kinder to the tissues of patients and to the skins of doctors and nurses" (Dowling, 1977, p. 40). Sanitary regulations that led to regulations governing water, sewage, and disposal systems contributed greatly to the control of certain infectious diseases which were transmitted by water, droplet infection, and bodily discharges. Pasteurization of milk and the regulations governing the care and management of cows contributed greatly to the demise of bovine type infections. As public health measures grew in sophistication and importance, certain diseases were not found in the cities but seemed to be rural problems (Leavell, 1958; Fox et al., 1970).

Typhaidwas a disease which could be controlled by sanitary 

measures, but if uncontrolled, could lead to disaster. In rural America the battle against typhoid as well as other diseases transmitted by the oral-fecal route was waged by educational campaigns and attempts to enforce sanitary regulations. Yet from 1959 to 1961, the incidence of typhoid was higher in rural areas (11.9 per 100,000 population) compared to urban areas (2.1 per 100,000 population). "Typhoid Mary" (Mary Mallon), a cook in New York City, acquired notoriety for illustrating how the disease is transmitted from a relatively healthy carrier. Causing seven epidemics in six years, she was virtually a "living culture tube in which germs of typhoid multiplied" (Dowling, 1977, p. 17). The experience of typhoid demonstrated that control measures can be readily applied to fecal-oral carriers through protective measures. This was not the case with diphtheria, the subject of the present research problem.

Diphtheria, caused by the bacillus corynebacterium diphtheria, produces a disease that is transmitted by the respiratory route. The disease may not always be cultured and is carried by people who may be exposed to large numbers of adults and children. The infection caused by diphtheria produces a false membrane in the throat. Bacilli lodge on the membrane, kill the cells causing the blood vessels to pour out fluid which clots and covers the surface, trapping the bacilli along with white blood cells and the remains of the surface cells. According to Dowling, this tough layer may 
extend over the larynx cutting off the oxygen supply to the lungs and suffocating the patient (Dowling, 1977). Thus the name "morbus strangulatoris" was given to this often fatal disease.

In 1919, New York was the leader in initiating a program of testing to identify those with no immunity to diphtheria. The Schick Test (named for Bela Schick of Vienna) consists of an injection of a small quantity of diphtheria toxin under the skin. In patients with no circulating antitoxin, and hence no evidence of immunity, an inflammatory reaction appeared at the site of the injection, indicating a positive test. Those with positive tests were then immunized. Problems in perfecting the vaccine persisted. However, it wasn't long before both diphtheria and tetanus were being used regularly in preventive programs. From 1930 to 1932 , the death rate for diphtheria in Chicago dropped from 12 per 100,000 to less than 2. This was accomplished by a system of immunization that took nurses into the homes, particularly seeking children under 5 years of age.

Tetanus antitoxin had an interesting history because of the nature of the vaccine. Most injuries that involved contamination by soil and the tetanus organism occurred in the country. When such rural accidents occurred, they were treated promptly by surgery and the injection of tetanus antitoxin. These tetanus producing injuries were relatively infrequent until the beginning of World War 1. Deaths recorded in the Death Registration area of the United States decreased from approximately 35 per million popula- 

tion during 1901-1905 to 7.2 per million from 1935-1939 (Dowling, 1977). The situation was totally different for those engaged in - the war. According to Dowling (1977), nearly 1 of 100 British soldiers developed tetanus in the early months of World War 1. The United States continued with prophylactic doses for those soldiers wounded. The drawbacks with treating after the injury are fairly obvious. The need for a preventative or active immunization program was identified as a major goal. By 1936, the French had a tetanus and diphtheria toxoid which they pioneered among civilians. By 1969, over half the inhabitants of the United States under the age of 20 had the complete immunization against diphtheria and tetanus; only $6 \%$ had received no immunization at all.

From 1950, when tetanus became a reportable disease, the number of cases dropped from about 500 to a low of 101 cases in 1973. In 1978, the cumulative total for tetanus reached 82 with most cases being reported in the south Atlantic states. Tetanus is a specified notifiable disease reported to the Center for Disease Control (CDC) in Atlanta (U.S. Department of Health, Education and Welfare, Public Health Service).

Whooping cough or pertussis shows a dramatic decline from 12 deaths per 100,000 population in 1900 to 0.0 deaths in 1970 . This mortality figure does not reflect the pain and suffering caused by the high incidence of this difficult disease. Measles 

also saw a drop in mortality from 13 deaths per 100,000 population in 1900 to 6.0 in 1970. Once again, the mortality figures do not reflect on the consequence of the illness, its sequella in febrile 1/Iness, deafness, and brain damage. By 1970, the major diseases causing death were the influenzas and pneumonia, as well as meningococcal infections (Dowling, 1977).

Infantile paralysis, or poliomyelitis, was an infectious disease of frightening proportions in the pre-immunization era. Striking primarily children and young adults it could cause damage to the brain stem (bulbar polio), or involve all or part of the spinal cord, resulting in paralysis of the muscles. When intercosta! muscles were affected, respiratory paralysis would result. Use of large respirators, called "iron lungs", was prevalent in infectious disease units until the 1960 s.

The Salk vaccine, discovered by Jonas Salk in the 1950s, was the first active immunization against poliomyelitis to be developed. It was tested in mass public poliomvelitis immunization programs throughout the United States in the late 1950s. Given in three different injections, it offered the first protection against Type 1, Type 11, and Type 111 poliomyelitis at a time when hospital wards were involved in tertiary care, the recovery of victims already stricken with the disease (Dowling, 1977).

Following the use of the Salk vaccine, a newer vaccine that 

could be administered by oral doses, was perfected in the laboratory. This vaccine, called "Sabin", was discovered by Albert D. Sabin in the 1960 s and soon replaced the Salk vaccine because of its efficacy in administration. Probably no vaccine in public health history was more dramatic in its use since the discovery of smallpox vaccine. It illustrated one of the finest examples of primary prevention - placing a barrier between the agent and the host that this modern era has seen. The poliomyel itis vaccines soon became required immunizations for school admission and the next 15 years were fairly free of a much dreaded disease. Despite efforts to protect the public health by mandatory regulations in most states, statistics reflect that epidemics still occur in the United States and worldwide (CDC, MMWR 27, 28, 1978).

Smallpox was last seen in Merka, Somalia, on October 26, 1977. Since that time active surveillance resulted in that country being declared smallpox-free with certification by an International Commission on Smallpox Eradication forthcoming in October of 1979 (should no further cases be discovered). Smallpox vaccination in this country was eliminated as a public health requirement in 1974. In the 5 years since this major decision, the United States has been free of this disease and it is no longer listed as a specified notifiable disease (CDC, MMWR $\underline{28}$, 1978) or even as a notifiable disease of low frequency. 

The diseases under investigation in this study are all specified notifiable diseases. Poliomyelitis cases for 1978 numbered 4, with 11 cases reported for 1977, of which 10 were paralytic (CDC, MMWR $\underline{27}(26), 1978)$. On an international level there were 38 virologically confirmed and 22 suspected cases of poliomyelitis among unvaccinated individuals from 5 of the Netherlands' 11 provinces were reported in the Morbidity and Mortal ity Weekly Report (CDC, MMWR $27(26), 1978)$. Of the 60 reported cases, 45 were with paralysis (Type I poliovirus) and 15 with aseptic meningitis. The index patient was a member of a community that does not accept vaccination because of religious beliefs. This epidemic occurred in a country in which approximately $95 \%$ of infants have received at least three doses of inactivated poliomyelitis vaccine in an effort to insure immunity in the entire Dutch population. An earlier outbreak in 1971 in the Netherlands was also traced to a population of individuals who refused to accept vaccination on the basis of religious beliefs. The Netherlands' outbreak in an unprotected community is an omen that apathy in securing immunization can lead to a similar situation in this country.

Bean, Burmeister, Paule, and Isacson (1978) express concern that poliomyelitis incidence as well as measles and rubella may again be climbing sharply. The reporting of 3,389 measles cases in January, 1977, preceded a major epidemic in California in the following spring (prior to their publication date) in which esti- 

mates of more than 10,000 cases were made. Measles is considered to be seriously underreported (CDC: Measles Surveillance, 1972 Summary) thus making it a far more serious public health problem than reported statistics indicate. Underreporting of notifiable diseases has long been identified as a serious block to public health surveillance (Hanlon, 1974; Leavell, 1958).

Bean et al. (1978) compared estimates of measles and rubella rates by studying the United States Immunization Survey (USIS), Morbidity and Mortal ity Weekly Reports (MMWR), the Health Interview Survey (HIS), and the Biologics Surveillance Reports. Based on discrepancies noted between these data estimates, the authors state:

This comparative study does not lend credence to the validity of any of the data sources. The USIS and HIS exhibit the same trend for estimated measles cases; however, the HIS estimate is consistently larger. The MMWR figures do not appear to be reliable national estimates ( $p .1215$ ).

They state that inherent difficulties in reporting rubella make the findings for that disease inconsistent. There seems to be agreement that despite difficulties in reporting all cases of these diseases, the incidence is still climbing at alarming rates in unprotected populations.

With the advent of air travel infectious diseases can spread quickly from country to country today. The rapidity with which measles can spread was demonstrated by a well-reported case in Utah of a 2 year old who had been enrolled in a daycare center two 

days prior to the onset of measles rash (CDC, MMWR, 28(2), 1978). Thirteen cases were subsequently diagnosed, all related to the index patient. The child had not been immunized previously because of bouts with chronic tonsillitis and had been exposed to measles in a daycare center in Australia prior to moving with his family to Utah. This case plus others points out that there is major concern over reports of measles cases in persons recently arrived in the United States from several countries in Europe, Asia, and North America. The Advisory Committee on Immunization Practices recommends immunization of young children in daycare center settings as particularly important. At this time there are no mandatory regulations for young children.

In a 1963 report on some 606 infants in Tennessee, it was found that $72 \%$ had received three injections of DTP before their second birthdays (Guthrie, 1963). However, only 37\% had received poliomyelitis injections. Guthrie concluded that it has previousIy been observed that more children of young mothers receive immunization than do those of older mothers. First-born infants began immunization earlier, received more injections and vaccinations, and achieved a higher percentage of immunization than do those who have an older sibling at birth. This study of the DTP status of 2 year old Negro infants noted a serious deficiency in immunization against poliomyelitis and a less serious but relatively unsatisfactory level of smallpox vaccination. For many 
infants the beginning of immunization is delayed past the recommended 2 or 3 months. Guthrie concluded that these deficiencies require that new or more intensive efforts be made to improve the immunization levels of Negro infants in Tennessee. Bassili and Stewart (1976) identified the role of adverse socio-economic conditions in the incidence of whooping cough in Scotland. They believed that selective immunization of highrisk groups is preferable to continuing mass immunization programs.

Hayden, Preblud, Orenstein, and Conrad (1978) reported that the decline in mumps in the United States to "all time low levels" is reason enough to incorporate mumps into a combined measles-mumps-rubel la vaccine for regular and required immunizaion. The unofficial 1977 total of 20,123 cases represents an additional 48\% decrease from the 1976 total. According to Hayden et al., the disease incidence has now reached the lowest point in the history of mumps surveillance.

Bussey and Holmes (1977), in a study of immunization levels for 1970-1976 in West Sussex, England, noted a national decline in immunization levels against pertussis (whooping cough) in 1974, 1975, and 1976. In contrast to the national experience, levels of immunization against diphtheria, tetanus, poliomyelitis or measles did not decline. Bussey and Holmes suggested that this difference is accounted for by the use of a computer system which keeps an "immunization diary" for parents and for medical and 

(1) 
nursing staff. Their plaintive title is worthy of mention: "Immunization Levels - Need They All Decline?"

In a recent survey of public attitudes toward immunization (Gunn, 1978a) which attempted to determine the relationship between past experience with vaccinations and future intent to be immunized, it was found that:

1. Although adults generally feel that these diseases are serious and have faith in the safety of available vaccines, there is a general lethargy and feeling of "it can't happen here" and "it can't happen to me or my children." These attitudes appear to prevent the motivation necessary for people to get immunized. People's theoretical beliefs about immunization in general and actual personal practices can be two very different things.

2. Data also suggest that behavior and beliefs about influenza vaccines are different from behavior and beliefs about vaccines for other diseases.

Among the adults interviewed in the sample of more than 4,000 households, it was found that race is the most important discriminant variable in predicting intent to immunize. Whites are more likely than non-whites to respond that they do not plan to receive immunizations during the next 12 months.

Other important variables in this nationwide study are:

- perceived likelihood of local occurrence of the disease

- perceived personal susceptibility

- perceived seriousness of the disease 
Among children, age is the most highly significant variable for poliomyelitis, measles, and DTP. Older children were in the "donot-intend-to-immunize" populations (Gunn, 1978b).

Further findings are that in the case of DTP, perceived seriousness of pertussis is the second most significant discriminant variable. For poliomyelitis and measles, race is the second most discriminant variable. Whites appear in the "do-notintend" population at a greater rate than do non-whites. As with adults, greater accuracy in prediction occurs when predicting the "do-not-intend" populations (Gunn, 1978b).

In an attempt to study three techniques for raising immunization levels in school age children, Vernon, Conner, Shaw, Lampe, and Doster (1976) found that in terms of how the school nurse's time is best spent, review of unimmunized records with notes sent to attend a school-based clinic got the best results. Sending permission slips to all children was second, while a health education program was found to be least effective of the three methods studied.

Anthony, Reed, Leff, Huffer, and Stephens (1977) reported on the success of law enforcement. The Cincinnati Board of Health and Board of Education had for the previous two years enforced the Onio Board of Health's legal authority to require immunization for children entering school. Ohio, 1 of 46 states requiring specific immunization before school entry, was successful in raising levels 

of an inadequately immunized school population. Witte (1974) particularly feared the national decline in poliomyelitis noting that the adequacy of infant immunization in the United States looms as a major health care del ivery problem.

Current statistics from the Communicable Disease Center show that despite preventive efforts and public health programs there are still hundreds of children contracting diphtheria, a notoriously dangerous upper respiratory disease, as well as thousands contracting pertussis or whooping cough (CDC, 1977, 1978). Over 100 cases of tetanus are seen annually, while measles and rubella lead the list of preventable diseases with nearly 25,000 to 50,000 cases reported annually in the united States (CDC, MMWR $\underline{28}, 1978$ ).

The problems associated with declining levels of immunization protection in a vulnerable population are clearly a serious public health threat. It is essential to delineate factors that will motivate people to take certain positive actions while healthy and relatively free of symptoms.

\section{Summary of the Review of Literature}

The review of the literature has attempted to seek out current knowledge on health locus of control, the Health Belief Model, and health behavior as it related to mothers of dependent children. The intent was to find salient information that could contribute to 

information about the factors influencing mothers in providing immunizations for their children. 

CHAPTER । ।

METHODOLOGY

\section{Subjects}

Subjects for this study were mothers of preschool children. The subjects were selected from a population of mothers who had a child between the ages of 2 to 6 years of age and who had their child enrolled in preschool for the academic year 1979-1980 at the Head Start Program of the Bernaliilo County Office of Educational Opportunity located in Albuquerque, New Mexico, (Appendix G).

The population of mothers for the study was approximately 400. A systematic random sampling procedure was used to select 100 mothers for the study. Lists of students attending the six Head Start Centers were compiled and the names of students were assigned numbers from 1 to 400 . The numbers for the random sample selection were computer generated. Approximately 200 mothers were contacted by telephone or letter before a sample of 100 subjects was obtained. Complete data was gathered on 94 subjects (Appendix H). Descriptive data was gathered on 95 subjects. 

The average mother who participated in this study was Hispanic, of low income and education level, Catholic, and 28 - years of age. After data collection, the subjects were divided into two categories: compliant or non-compliant. There were 51 mothers in the compliant category and 43 in the non-compliant category. There was one subject for whom immunization data was not available.

\section{Instruments}

The instruments used for this study were the following:

1. Demographic Data Collection Instrument (Appendix B)

2. The Health Value Scale (Appendix C)

3. The Multidimensional Health Locus of Control Scale (Appendix D)

4. The Communicable Disease Vulnerability Scale (Appendix E).

\section{The Demographic Data Collection Instrument}

This instrument was used to collect the demographic data needed to determine the level of compliance or non-compliance in providing required immunizations for preschoolers as well as information on the variables to be analyzed in this study as they related to the mothers:

1. age 

2. education

3. ethnicity

4. income

5. religion

6. ability to recall the poliomyelitis epidemics.

During the pilot testing of the instrument, no major problems were identified; however, several minor changes were made. The operational definition of the terms compliant and non-compliant were altered so that delayed compliance could be logically included in the category of compliant. During the pilot testing it became apparent that many subjects had delayed dates but they had actua!ly complied with requests by physicians or public health nurses. All immunizations had been given before the age of 2 , which is quite different from the non-compliant category in which required immunizations were not given nor was there any medical or nursing justification offered.

Although no objections were verbalized during the pilot testing, when the study was conducted, several subjects objected to the use of the term Protestant to represent Christian. Their religious preference was categorized under "other" because of this objection.

\section{Health Value Scale}

The Health Value Scale used in this study was a modification 
of Rokeach's Value Survey (Wallston, Wallston, and DeVellis, 1978b). The scale lists 10 values which the respondent is to rank according to preference. Listing health among the top 4 of 10 values has been interpreted by the authors as valuing health (Appendix B).

Rotter's social learning theory states that the likelihood of a behavior's occurrence is a function of the expectancy that the behavior will lead to an outcome and the reward value of the outcome. The MHLC is the expectancy measure, while the Health Value Scale is the health value measure. There are no reports on validity or reliability of this scale (Wallston, correspondence, 1978d). Some of the items to be listed are freedom, happiness, a sense of accomplishment.

The Health Value Scale was pilot tested on the same group of mothers as the MHLC instrument. Since no difficulties were revealed during the pilot study, the MHLC instrument was used in the original form. Results of the pilot testing showed that 17 of the 19 subjects ranked health as one of their first 4 choices. The two who did not both commented that they "would have but did not see it" until the test was completed.

\section{Multidimensional Health Locus of Control Scale}

The development of the Multidimensional Health Locus of Control Scale (MHLC) was based on an earlier scale designed to tap beliefs that the source of reinforcements for health related be- 

haviors is either primarily internal, a matter of chance, or under the control of powerful others (Appendix A). According to Walliston et al. (1978b), the MHLC is a more useful instrument than the original Health Locus of Control Scales. The MHLC was designed for use with adults having a minimum of an eighth grade education and no functional learning impairments. Wallston and Wallston (1978b) tested both forms A and B for reliability and validity with several other previously prepared locus of control scales. Alpha reliabilities for the MHLC ( 6 item form) ranged from .673 to .767 . However, when the 6 items in each scale were combined to 12 items, the alpha reliabilities increased from .830 to .859. The mean scores of forms $A$ and $B$ of the MHLC were nearly identical.

Since this study did not require the retaking of the test for comparative purposes, only form A was used. Form A has .767 alpha reliability for the Internal Health Locus of Control (MHLC) subscale. Wallston and Wallston developed the scale by investigating a population of adults over the age of 16 who were waiting at gates in a metropolitan airport. Two hundred and eighty-two persons $(49 \%$ males, $90 \%$ whites) of a total of 354 who were approached and asked to complete the survey did so. The subjects ranged in age from 35 to 44 , and $74 \%$ had at least some college education. The responses of the 115 subjects who returned the test forms were used for the development of the MHLC (WalIston 

et al., 1978b).

As an indication of predictive validity, correlations were computed between health status and the MHLC scores. Health status correlated positively with the Internal Health Locus of Control subscale $(r=.403, p<.001)$, negatively with the Chance Health Locus of Control subscale $(r=-.275, p<.01)$ and did not correlate with the Powerful Others Health Locus of Control subscale $(r=-.055)$ (Wallston and Wallston, 1978b).

The MHLC Scale used in this study was a development following the original unidimensional Health Locus of Control Scale. According to Wallston and Wallston (correspondence, 1978d), additional normative data have been collected (see Appendix C). Groups from which data have been collected are 57 males and 58 females in a community of Nashville, Tennessee, 167 males and females attending a YMCA health fair, and 97 graduate and professional women and 242 clerical women. Ages for the participants range from 29 to 44 . Means for the internality subscale range from 23.51 for the clerical women to 28.26 for the men attending the YMCA health fair.

Form $A$ of the MHLC was administered to a sample of 19 mothers of preschool children. These mothers were selected for pilot testing the instruments in this study because their characteristics were similar to the characteristics of subjects participating in the study. 
Results from the MHLC instrument revealed lit+le difficulty in administering the instrument. On all subscales the sample had higher scores than those of the normative data (see Appendix H). Subjects in the pilot study were higher on chance, internality, and powerful others. Although expressly designed for those with at least an eighth grade education, use of words such as behavior and control were singled out for a definition.

\section{The Communicable Disease Perceived Vulnerability Scale}

The Communicable Disease Perceived Vulnerability Scale, designed to examine beliefs about susceptibility to the specific diseases being studied, was tested for both validity and reliability as part of the pilot stage of this research study.

A panel of experts from New Mexico was asked to read and judge the instrument for content validity and construct validity. A physician in public health, three practicing community health nurses, a professor in family medicine, and a professor in community health education adjudged the instrument to be truly measuring beliefs about perceived vulnerability or susceptibility to the specific diseases in question. Minor changes in format were made, but the original scale as developed by the researcher for this study was maintained (Appendix D).

The scale consists of six questions pertaining to the mother's perception of the vulnerability of her child to selected communicable diseases. For each question on the scale the mother 

was asked to select one response from five alternatives. The scoring was based on a Likert-type scale ranging from "no chance" to "certain chance" of vulnerability. The questions are similar to those posed in earlier studies (Hochbaum, 1958; Gochman, 1972; and Gunn, 1978a). Perceived vulnerability refers to a person's expectancy of being susceptible to some health problem. High levels of perceived vulnerability along with perceived seriousness and perceived benefits presumably interact to increase the likelihood of a person taking or intending to take some specific health action. Gochman (1972) assessed perceived vulnerability by asking "What chance is there of your getting the flu during this next year?" (Gochman, 1972, p. 285).

In the early stages of research on predictor tests or hypothesized measures of a construct, it is acceptable to use instruments that have modest reliability (Stone, 1976). For these purposes, reliabilities of .60 or .50 or lower were accepted. The Perceived Vulnerability Scale was tested and then retested 10 days to 2 weeks later for reliability - to determine if similar results would be obtained. Nineteen subjects were originally enrolled for participation. Results were based on returns from 14 subjects who completed both the first test and then repeated the same scale two weeks later for test-retest reliability.

The Pearson Correlation Coefficient was used to analyze the 

data which were specific for each disease under study. Reliability for diphtheria was .68; tetanus, .79; poliomyelitis, .54; measles, .49; rubella, .31; pertussis, .68. Reliability for the total scale, obtained by combining the scores for the individual diseases and correlating them with repeated scores by the same subjects two weeks later, revealed an overall reliability of 0.71 as measured by the Pearson Correlation Coefficient (Appendix 1). A reliability of 0.71 is quite acceptable explaining $50.41 \%$ of the variance. According to Arey and Jacobs (1976) the square of the Pearson Coefficient represents the proportion of the variance of one variable that may be accounted for by its relationship with the other variable and vice versa.

\section{Design of the Study}

This study was a descriptive correlational study in that it was an investigation directed at obtaining facts and arriving at judgments pertaining to existing phenomena. Some of the typical sources of information employed in this descriptive study were 95 personal interviews, comparisons, correlations, and evaluation of data. Since the source of information was also derived from measurement of independent and dependent variables in an attempt to establish functional relationships among variables while the treatment was not under the direct control of the investigator, the study could also be termed ex post facto (Castetter and Heisler, 1977). 



\section{Procedures}

Procedures for this study were divided into three phases. Phase one included Human Subjects Review clearance, pilot testing of all instruments, and reliability testing of the Communicable Disease Perceived Vulnerability Scale, an original scale developed for this study. Phase two included data collection, and phase three included data analysis and preparation of the findings. All three phases will be discussed separately.

\section{Phase One}

Clearance from the University of New Mexico's Human Subjects Committee was obtained prior to beginning the actual data collection. Complete pilot testing of all interview procedures and instruments took place at the Rehabilitation Center in Albuquerque, New Mexico, one month before the study began.

A sample of mothers similar in ethnic composition, age, and income was used to pilot test all instruments for this study and to test-retest the Communicable Disease Perceived Vulnerability Scale (Appendix J). Twenty-six mothers from the Rehabilitation Center in Albuquerque, New Mexico, began the pilot testing. Data from 19 subjects were used for analysis of the pilot testing while data from 14 were used for the test-retest reliability of the 

Communicable Disease Perceived Vulnerability Scale. Five subjects did not return for the second phase of the reliability testing. Pilot testing findings revealed that there were 10 SpanishAmerican mothers $(52.6 \%), 8$ Anglo $(42.1 \%)$, and 1 other (5.3\%). In terms of religion, 8 (42.1\%) were Catholic, 8 (42.1\%) were Protestant, $1(5.3 \%)$ was Jewish, and $2(10.5 \%)$ selected other (Appendix J) as their religious preference.

The age range was 24 to 45 years of age with a mean of 28.58 , a median of 27.25 , and a mode of 24 . In terms of income, this group was found to be higher than those subjects in the actual study with $63.2 \%$ reporting income over $\$ 10,000$ but less than $\$ 20,000$. Five or $26.3 \%$ reported income of less than $\$ 10,000$, and two $(10.5 \%)$ reported income of more than $\$ 20,000$ (Appendix J).

\section{Phase Two}

This phase involved the actual data collection for the study. The investigator trained two assistants in administering the instruments. The first was a graduate student in nursing who assisted with interviews at the Head Start Center; the second was a graduate nurse who assisted the primary investigator in making home interviews to collect data. All personal interviews were conducted in either the Head Start Center or during a home interview. Consent forms were read, signed, and collected prior to conducting the interview. Official immunization records were required for participation. Each interview took approximately 20 minutes, with additional 

time provided to advise on any immunizations needed or to assist with advice or referrals regarding health or family problems. Completed data from 95 subjects were available for data analysis.

\section{Phase Three}

This was the data analysis phase of the research project. Data collected were organized by the researcher for subsequent key punching and verification. The Statistical Package for the Social Sciences (SPSS) series of computer programs was used for all of the computer analyses (Nie, Hull, Jenkins, Steinbrenner, and Bent, 1975). Analyses were carried out on an IBM 360 computer located at the Computing Center of the University of New Mexico in Albuquerque, New Mexico. 

CHAPTER IV

\section{ANALYSIS OF DATA}

The Statistical Package for the Social Sciences (SPSS), an integrated system of computer programs designed for the analysis of social science data, was used to analyze the data in this study. Descriptive statistics were used where appropriate (Nie, Hull, Jenkins, Steinbrenner, and Bent, 1975) (Appendix K).

Data analysis included descriptive statistics, Pearson productmoment correlation, chi-square analysis, and analysis of variance. While emphasis was placed upon the testing of hypotheses associated with the major questions raised, additional hypotheses were also tested. All hypotheses were tested at the .05 level of significance. Results related to the major hypotheses that were tested will be discussed first, followed by discussion of the secondary hypotheses which include data analyses of the variables of age, ethnicity, religion, education, income, and perceived vulnerability to the six diseases under study.

The first hypothesis which stated that there would be a significant difference on locus of control orientation, as measured by the Multidimensional Health Locus of Control Scaie (MHLC), between compliant and non-compliant mothers in regard to obtaining immuniza- 

tions for their preschoolers was not accepted. The 41 non-compliant subjects were less internal than the 49 compliant subjects but this finding was not statistically significant according to testing by analysis of variance. Table 1 shows the $F$ value as nonsignificant, $\underline{F}(1,88)=1.53, p=0.22$.

In comparing these findings with the normative data from the Wallston study (1978b), the means for both studies are almost identical. The Wallston study mean was 25.10 and the total sample mean from this study was 25.93 .

The second subscale chance of the MHLC Scale measured the dimension of externality. Analysis of variance between compliant and non-compliant groups (Table 2) shows that there was no statistically significant difference between groups, $\underline{E}(1,87)=0.09$, $p=0.77$.

Table 3 shows a major difference between this study sample and the sample from which the normative data were drawn $(t=3.51$, $p<.001)$. In the Wallston study $(1978 b)$, the mean was 15.57 for the subscale of chance with a standard deviation of 5.75 . The total or combined sample of compliant and non-compliant mothers in the current study shows a more external orientation with a mean of 18.56 and a standard deviation of 6.18 . The difference between the present sample and the normative sample is statistically significant. This sample of predominantly Spanish-American women is far more external on the internal-external locus of control scale than the normative sample. This is an important finding which is discussed in detail in the 

Table 1

Descriptive Statistics and Analysis of Variance

Between Compliant and Non-Compl iant Groups

on the Subscale of Internality

\begin{tabular}{lcccc}
\hline Measure & $\begin{array}{c}\text { Non-Compl iant } \\
N=41\end{array}$ & $\begin{array}{c}\text { Compliant } \\
N=49\end{array}$ \\
\hline Internality & $\bar{X}$ & S.D. & $\bar{X}$ & S.D. \\
Total Sample & 25.15 & 6.94 & 26.71 & 5.05 \\
\hline
\end{tabular}

\begin{tabular}{lcrrrrr}
\hline Source & $\begin{array}{c}\text { Degrees of } \\
\text { Freedom }\end{array}$ & $\begin{array}{c}\text { Sum of } \\
\text { Squares }\end{array}$ & $\begin{array}{c}\text { Mean } \\
\text { Squares }\end{array}$ & $\begin{array}{c}F \\
\text { Ratio }\end{array}$ & $\begin{array}{c}F \\
\text { Prob. }\end{array}$ \\
\hline Between Groups & 1 & 54.86 & 54.86 & 1.53 & 0.22 \\
Within Groups & $\underline{88}$ & 3151.11 & 36.57 & & \\
\multicolumn{1}{c}{ Total } & 89 & & & & \\
\hline
\end{tabular}

$\begin{array}{lcccc}\text { Normative Data } & N & \bar{X} & \text { S.D. } \\ \text { Wallston Sample } & 115 & 25.10 & 4.89\end{array}$

Source: Wallston, Wallston, and DeVellis, 1978b 

Table 2

Descriptive Statistics and Analysis of Variance

on the Subscale of Chance for Compliant

and Non-Compliant Groups and the

Normative Data Group

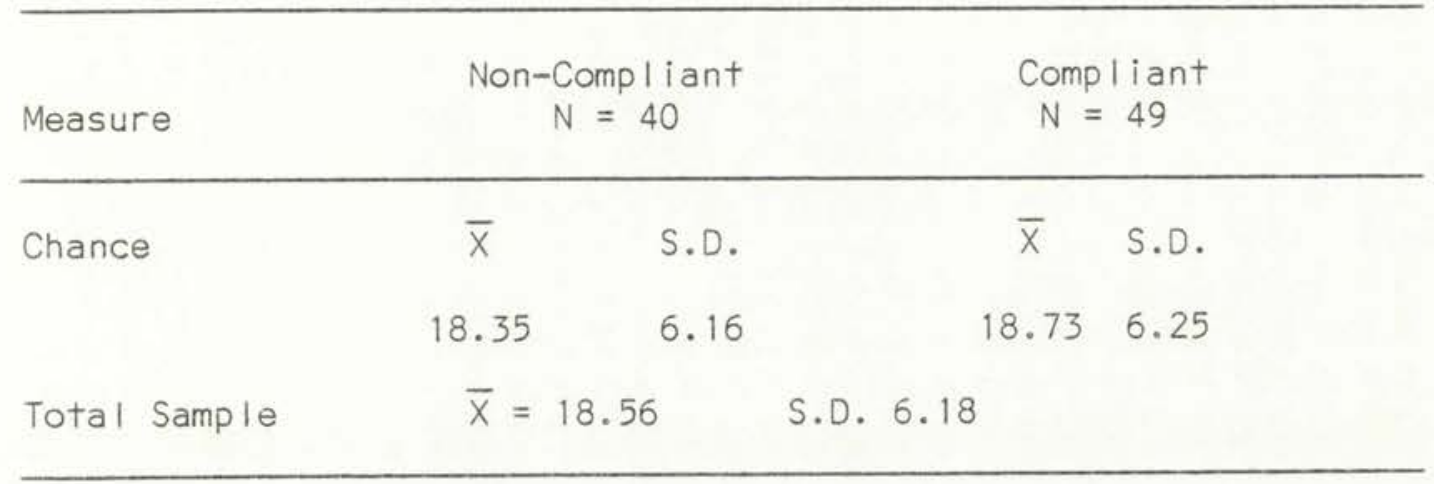

\begin{tabular}{lcrrrr}
\hline Source & $\begin{array}{c}\text { Degrees of } \\
\text { Freedom }\end{array}$ & $\begin{array}{r}\text { Sum of } \\
\text { Squares }\end{array}$ & $\begin{array}{c}\text { Mean } \\
\text { Squares }\end{array}$ & $\begin{array}{c}F \\
\text { Ratio }\end{array}$ & $\begin{array}{c}F \\
\text { Prob. }\end{array}$ \\
\hline Between Groups & 1 & 3.26 & 3.26 & 0.09 & 0.77 \\
Within Groups & $\underline{87}$ & $\underline{3358.64}$ & 38.61 & & \\
Total & 88 & 3361.90 & & \\
\hline Normative Data & $N$ & $\bar{X}$ & S.D. & & \\
Wallston Sample & 115 & 15.57 & 5.75 &
\end{tabular}

Source: Wallston, Wallston, and DeVellis, 1978b 

Table 3

Comparison of Means on Subscale of Chance

with Original Multidimensional Health Locus of Control.

Normative Data

Wal Iston Study ${ }^{a}$

Present Sample

$N=115$

$N=89$

\section{$\bar{x}$}

S.D.

$\bar{x}$

S.D.

15.57

5.75

18.56

6.18

+ Value $=3.51$

$p=<.001$

a Source: Wallston, Wallston, and DeVellis, 1978b 

discussion and conclusions chapter (Chapter V). The Multidimensional Health Locus of Control Scale has no overall score, but, instead, examines different parameters of the internal-external orientation by use of the subscales. This predominantly female, poor, SpanishAmerican sample scored far more external on the chance parameter than the original Wallston (1978b) sample upon which the data were analyzed. There was no statistically significant difference between the compliant and non-compliant groups and the normative data group, as measured by the third subscale (Powerful Others) of the MHLC Scale in regard to obtaining immunizations for their preschoolers, $\underline{F}(1,89)=0.15, p=0.70($ Table 4$)$.

The second major hypothesis stated that there would be a significant difference on value of health, as measured by the Health Value Scale, between the 43 compliant and 51 non-compliant subjects in regard to obtaining immunizations for their children. Analysis of variance between the means for these two groups yielded no significant difference between the groups, $\underline{F}(1,92)=0.24, p=0.62$ (Table 5).

In the original health locus of control studies, ranking health as one of the first 4 values on the 10 item Health Value Scale was considered to indicate that the individual placed a high value on health and was considered critical to the Rotter social learning construct. Table 5 indicates that both groups, compliant and non-compliant, ranked heaith high on the vaiue scale. Health was the value ranked highest by most subjects. More than $94.6 \%$ 

Table 4

Descriptive Statistics and Analysis of Variance

on the Subscale of Powerful Others for Compliant and Non-

Compliant Groups and the Normative Data Group

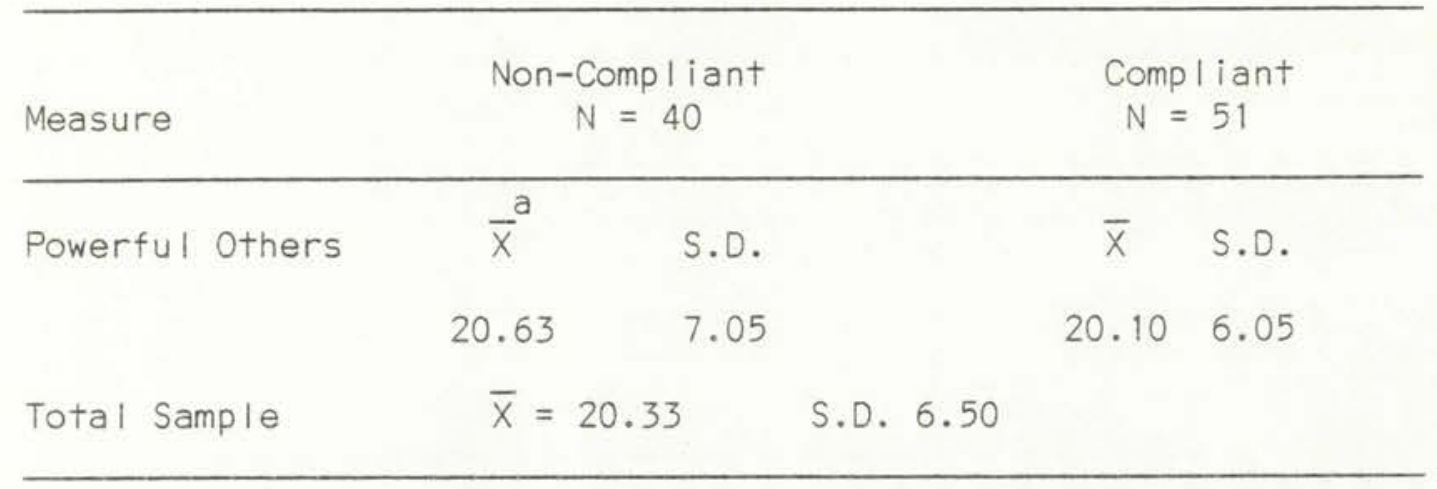

\begin{tabular}{|c|c|c|c|c|c|}
\hline Source & $\begin{array}{c}\text { Degrees of } \\
\text { Freedom }\end{array}$ & $\begin{array}{r}\text { Sum of } \\
\text { Squares }\end{array}$ & $\begin{array}{l}\text { Mean } \\
\text { Squares }\end{array}$ & $\begin{array}{c}F \\
\text { Ratio }\end{array}$ & $\begin{array}{c}\text { F } \\
\text { Prob. }\end{array}$ \\
\hline Between Groups & 1 & 6.23 & 6.23 & 0.15 & 0.70 \\
\hline Within Groups & 89 & 3769.88 & 42.36 & & \\
\hline Total & 90 & 3776.11 & & & \\
\hline a Normative Data & $\mathrm{N}$ & $\bar{x}$ & & & \\
\hline Wallston Sample & 115 & 19.99 & & & \\
\hline
\end{tabular}

Source: Wallston, Wallston, and DeVellis, 1978b 

Table 5

Descriptive Statistics and Analysis of Variance of

Compliant and Non-Compliant Groups in the

Selection of Health as a Value

\begin{tabular}{lccc}
\hline Groups & Number & $\begin{array}{c}\text { Mean } \\
\text { of the Ranks }\end{array}$ & S.D. \\
\hline Non-Compliant & 43 & 2.07 & 1.65 \\
Compliant & $\underline{51}$ & $\underline{1.90}$ & 1.63 \\
& 94 & 1.98 & \\
\hline
\end{tabular}

\begin{tabular}{lccccc}
\hline Source & $\begin{array}{c}\text { Degrees of } \\
\text { Freedom }\end{array}$ & $\begin{array}{c}\text { Sum of } \\
\text { Squares }\end{array}$ & $\begin{array}{c}\text { Mean } \\
\text { Squares }\end{array}$ & $\begin{array}{c}F \\
\text { Ratio }\end{array}$ & $\begin{array}{c}F \\
\text { Prob. }\end{array}$ \\
\hline Between Groups & 1 & 0.66 & 0.65 & 0.24 & 0.62 \\
Within Groups & $\underline{92}$ & $\underline{247.30}$ & 2.68 & & \\
Total & 93 & 247.96 & & \\
\hline
\end{tabular}



ranked health higher than the fourth place. Compliant subjects ranked health higher than did non-compliant subjects, but this finding was not statistically significant. More than half the total sample (54\%) selected health as their number one value, followed by $20 \%$ who selected it second. Only 5 of the 95 mothers placed health lower than the fourth ranking as their fifth or sixth choice. Other first choices, in order of ranking, were happiness, a comfortable life, respect, harmony, a sense of accomplishment, an exciting life, pleasure, recognition, and freedom.

Analysis of variance between groups showed that there was no statistically significant difference based on selecting health as a value. The hypothesis that there would be a significant difference between compliant and non-compliant groups as measured by the Health Value Scale was not accepted.

The third major hypothesis stated was that there would be a significant difference on perceived vulnerability as measured by the Communicable Disease Perceived Vulnerability Scale between both groups of mothers in regard to obtaining immunization for their preschoolers. Data analysis was based on combining responses from no chance to almost no chance as one category and combining the three categories of some chance, almost certain, and certain as the other category.

In terms of perceived vulnerability to the six diseases under 
study, more subjects reported feeling vulnerable than did not. Out of 93 subjects, 69 reported feeling vulnerable to diphtheria compared to 25 who reported not feeling vulnerable. For pertussis, 75 reported feeling vulnerable compared to 18 who did not. Eighty subjects reported feeling vulnerable to tetanus while the remaining 11 did not report feeling vulnerable. Seventy subjects reported feeling vulnerable to poliomyelitis while 23 did not report vulnerability to that disease. The lowest numbers reported perceived vulnerability to measles and rubella. Only 7 reported not feeling vulnerable to measles and 87 reported feeling vulnerable. Nine reported not feeling vulnerable to rubella while 85 reported vulnerability to that disease (Table 6).

The chi-square method of analysis was used to compare compliant and non-compliant mothers to determine if there was a relationship with perceived vulnerability. Out of the 93 subjects, 39 compliant and 30 non-compliant reported vulnerability to diphtheria, but the findings were not statistically significant $\left(x^{2}=.24,1 \mathrm{df}, p=0.61\right)$. Forty-two compliant and 33 non-compliant subjects reported vulnerability to pertussis but the findings were not statistically significant $\left(x^{2}=.04\right.$, I df, $\left.p=0.84\right)$. Forty-seven compliant subjects and 22 non-compliant subjects reported perceived vulnerability to tetanus but the findings were not statistically significant $\left(x^{2}=2.50,1 \mathrm{df}, p=.11\right)$. Forty compliant and 30 noncompliant subjects reported perceived vulnerability to poliomyelitis 



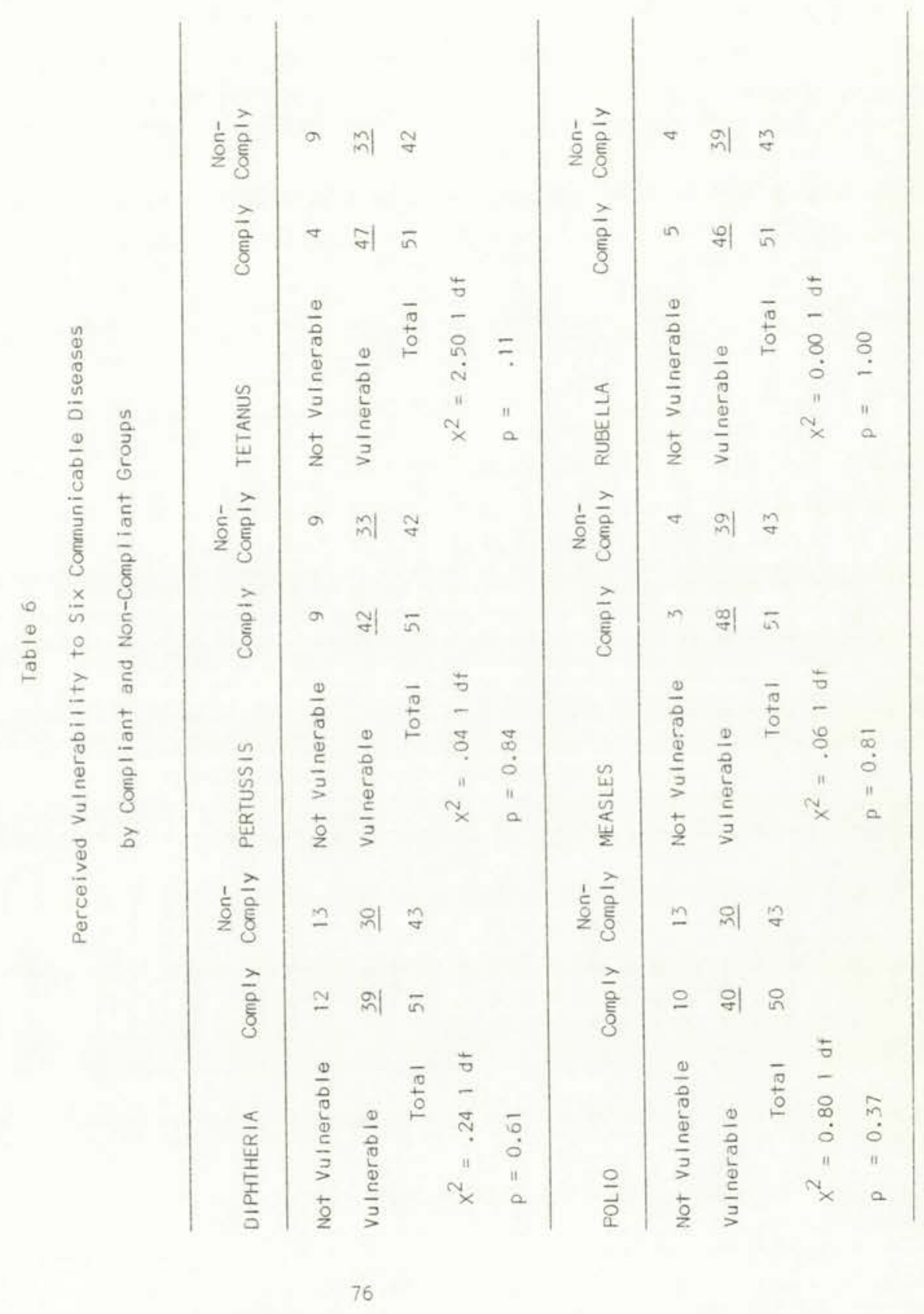


but the findings were not statistically significant $\left(x^{2}=.80,1 \mathrm{df}\right.$, $p=0.37)$. Forty-eight compliant and 39 non-compliant subjects reported perceived vulnerability to measles but the findings were not statistically significant $\left(x^{2}=.06,1 \mathrm{df}, p=0.81\right)$. The last disease studied was rubella for which 46 compliant and 39 noncompliant reported perceived vulnerability. The differences between the two last groups was also not statistically significant $\left(X^{2}=0.00\right.$, I df, $p=(.00)$.

The 51 compliant and 43 non-compliant subjects were asked to report on overall vulnerability to the six diseases combined.

Eighty-one subjects, or $86.2 \%$, reported feeling vulnerable while only 13 subjects $(13,8 \%)$ reported not feeling vu!nerable. Chi-square analyses of the two groups of compliant and non-compliant subjects detected no statistically significant difference between the groups $\left(x^{2}=0.86,1 \mathrm{df}, p=0.35\right)$.

In terms of data analysis on education, groups were combined as either high school or less in one group, and greater than high school in the other. Ethnicity was self-reported, and comparisons between Hispano or Spanish-American were made with other groups. Age was categorized either as 29 or younger, or 30 years of age or older. Recall of the poliomyelitis epidemics was based on: (1) personal first-hand recollection of the disease or epidemics; from knowing someone who was crippled by poliomyelitis; or (3) not having any recollection or knowledge of poliomyelitis at all. 

In terms of reported education, data were available on 95 subjects. Of the total subjects, $17.9 \%$ had less than a high school education, 32.6\% had some high school, there were $25.3 \%$ who were high school graduates, and $22.1 \%$ reported having some college. College graduates numbered $2.1 \%$. Table 7 includes two-by-two chi-square analyses showing that more subjects with a high school education fell into the compliant group, but these differences were not statistically significant $\left(x^{2}=1.54, d f=1, p=0.21\right)$. The hypothesis that level of education would show a statistically significant difference was not accepted.

In terms of ethnicity, descriptive data were available on 95 subjects. The sample was predominantly Spanish-American or Hispano (81.1\%), with 9.5\% Ang 10, 5.3\% Native American Indian, and less than $2.2 \%$ black or Oriental. Based on chi-square analysis there is no statistically significant difference on the basis of ethnicity between compliant and non-compliant groups. Since the group as a total is predominantly Spanish-American, there were not enough subjects in other groups to justify further data analysis or generalizations from that sparse data $\left(X^{2}=2.28\right.$, $d f=2, p=0.32)$. Since almost equal numbers of Spanish-Americans fell into the two groups, the hypothesis that ethnicity would be a significant factor in compliance versus non-compliance cannot be accepted (Table 8).

Descriptive data were available on 94 subjects with a range of age from 19 to 67 years. Descriptive statistics showed a mean 

Table 7

Chi-Square Analysis of Compliant and Non-Compl iant Mothers on the Basis of Education

\begin{tabular}{|c|c|c|c|}
\hline $\begin{array}{c}\text { Level } \\
\text { of } \\
\text { Education }\end{array}$ & $\begin{array}{l}\text { Non- } \\
\text { Compliant }\end{array}$ & Compliant & $\begin{array}{l}\text { Row } \\
\text { Total }\end{array}$ \\
\hline Less than High School & 25 & 22 & $47(50 \%)$ \\
\hline $\begin{array}{l}\text { High School Education } \\
\text { or above }\end{array}$ & 18 & $\underline{29}$ & $47(50 \%)$ \\
\hline Column Total & $\begin{array}{c}43 \\
(45.7 \%)\end{array}$ & $\begin{array}{c}51 \\
(54.3 \%)\end{array}$ & $\begin{array}{c}94 \\
(100 \%)\end{array}$ \\
\hline$x^{2}=1.541 \mathrm{df}$ & & & \\
\hline$p=0.21$ & & & \\
\hline
\end{tabular}



Table 8

Chi-Square Analysis of Compliant and Non-Compliant Mothers on the Basis of Ethnicity

\begin{tabular}{lccc}
\hline Ethnicity & $\begin{array}{c}\text { Non- } \\
\text { Compliant }\end{array}$ & Compliant & $\begin{array}{c}\text { Row } \\
\text { Total }\end{array}$ \\
\hline Spanish & 37 & 39 & $\begin{array}{c}76 \\
(80.9 \%)\end{array}$ \\
Anglo & 2 & 7 & $99.6 \%)$ \\
Other & 4 & 5 & 9 \\
& - & - & $(9.6 \%)$ \\
& 43 & 51 & 94 \\
& $(45.7 \%)$ & $(54.3 \%)$ & $(100 \%)$ \\
\hline
\end{tabular}

$x^{2}=2.28 \quad 2 d f$

$p=0.32$ 

age of 28.91 , a median of 27.69 , and a mode of 28 years. The standard deviation was 9.25 (Table 9). In using the chi-square method of statistical analysis with age, there was no significant difference in compliance based on the age of the subject $\left(x^{2}=0.14\right.$, $d f=1, p=0.71$ ). Almost equal numbers of mothers less than 30 years or older than 30 years fell into the two groups (Table 9). In terms of income, $90.4 \%$ reported incomes of less than $\$ 10,000$. One of the eligibility requirements for Head Start is poverty level income. There is a sliding scale for those earning above the $\$ 10,000$ level based on number of children in the family. There were $9.6 \%$ who reported incomes above $\$ 10,000$. The hypothesis that there would be a statistically different result based on income could not be supported (Table 10).

In terms of religion, $75.8 \%$ of this sample reported themselves to be of the Catholic religion; selecting Protestant were some $6.3 \%$. Almost equal numbers of Catholics were in both the compliant and the non-compliant groups; there were not enough subjects in the other cells to make statistical comparisons on the basis of religion. Because of the predominantly Catholic sample, the hypothesis that there would be a statistically significant difference on the basis of religion could not be accepted (Table 11). Descriptive data were available on 90 subjects regarding ability to recall the poliomyelitis epidemics of the 1950 s (Table 12). The hypothesis that recall of poliomyelitis would provide a statistically different result was not supported by this research 

Table 9

Chi-Square Analysis of Compliant and Non-Compliant

Mothers on the Basis of Age

\begin{tabular}{lccc}
\hline $\begin{array}{c}\text { Age of } \\
\text { Subjects }\end{array}$ & $\begin{array}{c}\text { Non- } \\
\text { Compliant }\end{array}$ & Compliant & $\begin{array}{c}\text { Row } \\
\text { Total }\end{array}$ \\
\hline $19-29$ years & 27 & 35 & $\begin{array}{c}62 \\
(66 \%)\end{array}$ \\
30 years or older & 16 & 16 & $\frac{32}{(34 \%)}$ \\
Column Total & -43 & -51 & 94 \\
$X^{2}=0.141 \mathrm{df}$ & $(45.7 \%)$ & $(54.3 \%)$ & \\
$P=0.71$ & & &
\end{tabular}


Table 10

Descriptive Data on Income for Total Sample

$N=95$

\begin{tabular}{|c|c|c|}
\hline Income Reported & Number & Percent \\
\hline Below $\$ 10,000$ & 85 & 90.4 \\
\hline$\$ 10,000$ or Above & 9 & 9.6 \\
\hline Unreported & 1 & 0 \\
\hline Total & 95 & $100 \%$ \\
\hline
\end{tabular}



Table 11

Descriptive Data on Religion for Total Sample

$$
N=95
$$

Religion Reported

Number

Percent

Catholic

72

75.8

Protestant

6

6.3

All Others

16

16.8

Unreported

1

1.1

Total

95

$100 \%$ 
Table 12

Chi-Square Analysis of Compliant and Non-Compliant Mothers on the Basis of Recall of Poliomyelitis

\begin{tabular}{lccc}
\hline $\begin{array}{l}\text { Poliomyelitis } \\
\text { Recall }\end{array}$ & $\begin{array}{c}\text { Non- } \\
\text { Compliant }\end{array}$ & Compliant & $\begin{array}{c}\text { Row } \\
\text { Total }\end{array}$ \\
\hline $\begin{array}{l}\text { Yes, personal } \\
\text { recall }\end{array}$ & 2 & 6 & 8 \\
$\begin{array}{l}\text { Yes, knew someone } \\
\text { with disease }\end{array}$ & 11 & $8.9 \%)$ & 22 \\
$\begin{array}{l}\text { No recall of } \\
\text { poliomyelitis }\end{array}$ & 29 & 11 & $(24.4 \%)$ \\
& - & 31 & 60 \\
Column Total & 42 & - & $(66.7 \%)$ \\
\hline
\end{tabular}

$x^{2}=1.672 \mathrm{df}$

$p=0.43$ 

$\left(x^{2}=1.67, d f=2, p=0.43\right)$. Of the 90 subjects who completed data on the recall of poliomyelitis, only six of the compliant group and two of the non-compliant group could recall the disease or its epidemics from personal experience. Eleven each from the compliant and non-compliant groups knew someone crippled by poliomyelitis. Some two-thirds of the entire sample had no recall or knowledge of the disease at all; thirty-one were in the compliant group, while 29 were in the non-compliant group. The chi-square method of analysis yielded no statistically significant difference between those who could recall poliomyelitis from those who could not. Therefore, the hypothesis was not accepted. 
CHAPTER $V$

DISCUSSION, CONCLUSIONS, AND RECOMMENDATIONS

This chapter contains a discussion of the research findings and conclusions. In addition, some recommendations for future research are suggested.

\section{Discussion}

The first hypothesis of the study indicated that there would be a significant difference between compliant and non-compliant subjects as measured by the Multidimensional Health Locus of Control scale. The scale was divided into three subscales which measured beliefs about internality versus externality, the role of chance, and the influence of powerful others. Results from the first subscale indicated subjects were almost evenly divided between those who reported an internal locus of control orientation and one that reflected externality. Previous research has been divided in reporting internality as an important variable related to health-seeking behavior (Saltzer, 1978). The present investigation did not support the findings from the previous studies that internality is correlated with positive health action 

as seen in immunization compliance.

The second subscale of the Multidimensional Health Locus of Control Scale measured beliefs about chance, or how one's health is influenced by fate or destiny. No significant differences were found between compliant and non-compliant mothers on the chance subscale. Most subjects revealed a high degree of external locus of control orientation as reflected by this measure. These results are not congruent with previous research studies. One explanation for the difference lies in the nature of the standardization sample of the original Wallston study (1978b).

In the wallston study subjects were randomly selected from a population located in a city airport. Forty-nine percent were males, $90 \%$ white, and $74 \%$ had a college education. More than half the sample were from the state of Tennessee. This standardization sample is vastly different from the totally female population in the current study, more than half of whom had less than a high school education. The subjects in the current study were significantly younger than those in the Wallston study (mean age of 28 versus 42). The majority of the subjects in the present study were Spanish-American and were predominantly of the Catholic faith, which might suggest an orientation toward externality as an influential force in the lives of these subjects.

The third subscale of the Multidimensional Health Locus of Control scale measured beliefs about the influence of powerful 

others in health behavior. An example of an item from this subscale is "I will remain well if I see an excellent physician." No differences between compliers and non-compliers were found on this measure. Overall scores of the current population studied were similar to those of the original Wallston study (1978b). This finding is congruent with a study conducted by Bullough (1972), in which the variables of education and income were identified as primarily related either to success or failure in preventive health behavior. Bullough studied a multicultural population (Spanish-American, black, and anglo) and reported that the poorest and least educated subjects (in this case SpanishAmerican women) were least likely to engage in preventive health care. One difference between the Bullough investigation and the current study is that the former study used self-reported compliance, while the present study required documented proof of immunization through valid health records. This may be a very important difference. Although an internal orientation has been frequently suggested as a predictor of preventive health behavior (Wallston, Wallston, and DeVellis, 1978b), it appears from Bullough's research and the current study that education and income level are more important considerations.

The second major hypothesis of the study was derived from Julian Rotter's social learning theory, which suggests that differences in compliance would be related to subjects' perceptions of 

health as an important value. Selecting health as one of the highest 4 of 10 stated values was established as meeting this criterion. Using immunization compliance as the dependent variable, no differences were found between compliant and non-compliant mothers. Health was selected as one of the top four values in $94.6 \%$ of all subjects, with compliant mothers selecting it slightly more frequently than their non-compliant counterparts.

Although health was ranked as very important, results of the current study indicated that attitudes and actual behavior are not highly correlated. Mothers may value health and want their children to remain healthy, but due to factors such as motivation or other health barriers may not be willing or able to engage in an activity such as immunization to promote these stated goals.

The third hypothesis under investigation was the role of perceived vulnerability in immunization behavior. Perceived vulnerability, which states that in order for a person to engage in preventive health behavior in an asymptomatic state the individual must believe he/she is susceptible to the disease in question, has been an accepted component of the Health Belief Model (Becker, 1974; Maiman et al., 1977; and Rosenstock, 1974). The findings from this study do not support this contention. Although the majority of subjects in this study reported a belief in the vulnerability of their children to six major disease categories, close to $50 \%$ of mothers were non-compliers with immunization procedures for their preschool child. 

Steele and McBroom (1972) raise serious questions about the present Health Belief Model. They propose that health behavior is a multidimensional rather than a unidimensional phenomenon. Kasl and Cobb (1966) also emphasize that psychological and sociological factors play a greater role in health behavior than attitudes and beliefs. They suggest demographic factors such as race, ethnicity, education, and socio-economic status must be considered as powerful forces. Support for this position comes from a study by Kegeles (1967) in which women took cancer detection tests for cervical cancer. Subjects who scored high on perceived vulnerability to cancer were typically white, better educated, and with higher incomes than those who scored low. The current study would suggest that similar demographic factors are important variables in assessing the immunization behavior of mothers, most of whom were lower socio-economic minority members with less than a high school education.

Education and income level were found by Green (1970) to be more highly correlated with poliomyel itis immunization than any other composite of variables. While education of the mother was found to be the predominant factor in the preventive health behavior of the white majority, family income proved to be more important in accounting for variations in the preventive health behavior of the non-white population. Green also states that the educational level of the mother is more highly correlated with 

family health behavior patterns than the education of the male head of household. Socio-economic status is also cited by Green (1970). He states that a mother of low socio-economic status is under less social pressure from her friends and neighbors to seek immunizations for her children than would be the typical middle class mother.

The present study supported earlier research on the importance of income level in influencing preventive health behavior. Income was predominantly low for this sample total group with most of the sample earning less than $\$ 10,000$ yearly. Rosenstock (1974) cautions public health workers to recognize that members of the lower socio-economic classes are not as prone to subscribe to the health beliefs that are accepted by middle class individuals. Future orientation, which is implied in health seeking behavior, is predominantly a middle class value. Rosenstock reports that even when immunizations are free, thus removing the financial barrier, poor families demonstrate a lower rate of protection than those with higher incomes. Steele and McBroom (1972) offer additional support for this conclusion in their study of 1600 subjects, which indicated that lower social class subjects were significantly less I ikely to make dental visits, obtain health insurance, see physicians, or seek physical examinations than middle class populations.

Rosenstock, Derryberry, and Carriger (1959) described two 

critical factors characterizing individuals who failed to seek poliomyelitis immunizations: personal readiness and situational conditions. This study has relevance for the present investigation, in that several mothers indicated that delays in seeking immunization for their children were due to such situational factors as moving from one residence to another and lack of transportation. A lack of persistence was also evidenced by many of the non-compliant subjects. To qualify for school entrance in this state children must receive immunizations on six different occasions. For purposes of this investigation, completion of five treatments was considered as reflecting compliance (three for the primary series, one each for the booster and for measles). Interviews with these mothers conveyed a consistent pattern that they believed a partial immunization schedule was sufficient to protect their child. Additionally, these women reflected strong dependence on health personnel to direct them with reference to scheduling. A typical comment heard during interviews was "I came back when the public health nurse told me to." Rather than reflecting an independent decision-making stance, these mothers seemed to need consistent external directions related to the providing of immunizations.

Another demographic factor warranting consideration in the previous study is the religious preference of the subjects. As previously stated, the majority of mothers listed their religion 
as Catholic $(76.6 \%)$. If the assumption is made that belief in the control of a higher power was reflected by this religious orientation, then it is not surprising that forces of chance, fate or destiny (externality) appeared in the responses of a sizeable number of subjects. Since no attempt was made to examine the degree of devoutness of the subject's religious beliefs, however, the matter warrants further research.

In response to questions about six major diseases, many of the subjects revealed they were unable to distinguish one disease from the other. Such lack of information was found in other studies. Gunn (1978a) reported parents frequently identify "rabies" as one of their children's "shots." In terms of recall of the poliomyelitis epidemics of the past, the present study indicated that two-thirds of the sample did not recall these episodes, had never associated with anyone who had poliomyelitis, nor had ever been told about the problem. It would appear from this limited sample that poliomyelitis is rapidly becoming or aiready is a forgotten disease.

It is important to note that this study did not accept anything but official health or immunization records for the dependent variable. Many previous studies have utilized telephone sampling which was self-report data. This study only utilized valid records collected during the personal interviews, which left no doubt as to the validity of the report. 



\section{Conclusions}

The following conclusions were reached in this study:

1. There was no difference in internality-externality or health locus of control orientation between compliant and noncompliant mothers as reflected in obtaining immunizations for their dependent preschool children.

2. Subjects were predominantly external in orientation as measured by the internality-externality scale of the Multidimensional Health Locus of Control Scale.

3. There was no difference between compliant and noncompliant mothers in their ranking of health as an importantly held value. Almost all of the mothers ranked health as an important value selecting it as their first or second choice.

4. There were no differences between compliant and noncompliant mothers based on perceived vulnerability to the six communicable diseases studied.

5. There were no differences between compliant and noncompliant subjects in age, ethnicity, religion, income, educational level, or ability to recall the poliomyelitis epidemics of the 1950 s.

\section{Recommendations for Future Research}

1. Future research efforts need to be directed toward collecting health locus of control data from members of other 

minority cultures, such as Indians and blacks, to substantiate the effects of minority group status on health behavior.

2. Future research on health locus of control orientation should be done utilizing quasi-experimental designs to determine if there is a difference in health action or activity based on reported locus of control orientation. The influence of religious values should be studied as part of this research to determine if certain religious preferences have an influence on actual health actions.

3. More research needs to be done on the relationship between health values and health actions. Current findings of this study indicated that perceived vulnerability was not related to providing immunizations. This may warrant further investigation and validation of the Health Belief Model, particularly as it pertains to the actions of minority group members.

4. Ways to foster and promote persistence and motivation critical to the successful completion of an immunization series need further investigation. With the diminution in the actual number of cases of communicable diseases, the entire concept of perceived vulnerability needs reexamination. It may be difficult for someone to fear a disease that is not part of that person's environment or past experience. Motivational methods not based on fear or the ability to recall a dreaded disease need to be investigated as ways of influencing positive health behavior. 
5. Research should be directed at studying the dependency expressed by many persons towards health providers. How much actual information should be shared with mothers of preschoolers at the initial visits for acquiring immunizations? What kinds of information should this be? There is a need to explore more effective ways to assist consumers in assuming more responsibility for their health care by providing appropriate information that is understandable and relevant.

6. This study needs to be replicated with Spanish-American subjects I iving in other parts of New Mexico and in states other than New Mexico (i.e., Texas, California, Arizona, Colorado), as weil as with other minority groups, to determine the generalizability of the results to these populations.

7. Research should be continued on the development of scales and tests that measure beliefs and attitudes - particularly in relation to health locus of control orientation and health value. Reilability testing and validation of these instruments is critical to establishing credibility in the use of such instruments. 

APPENDIGES 
APPENDIX A 

APPENDIX A
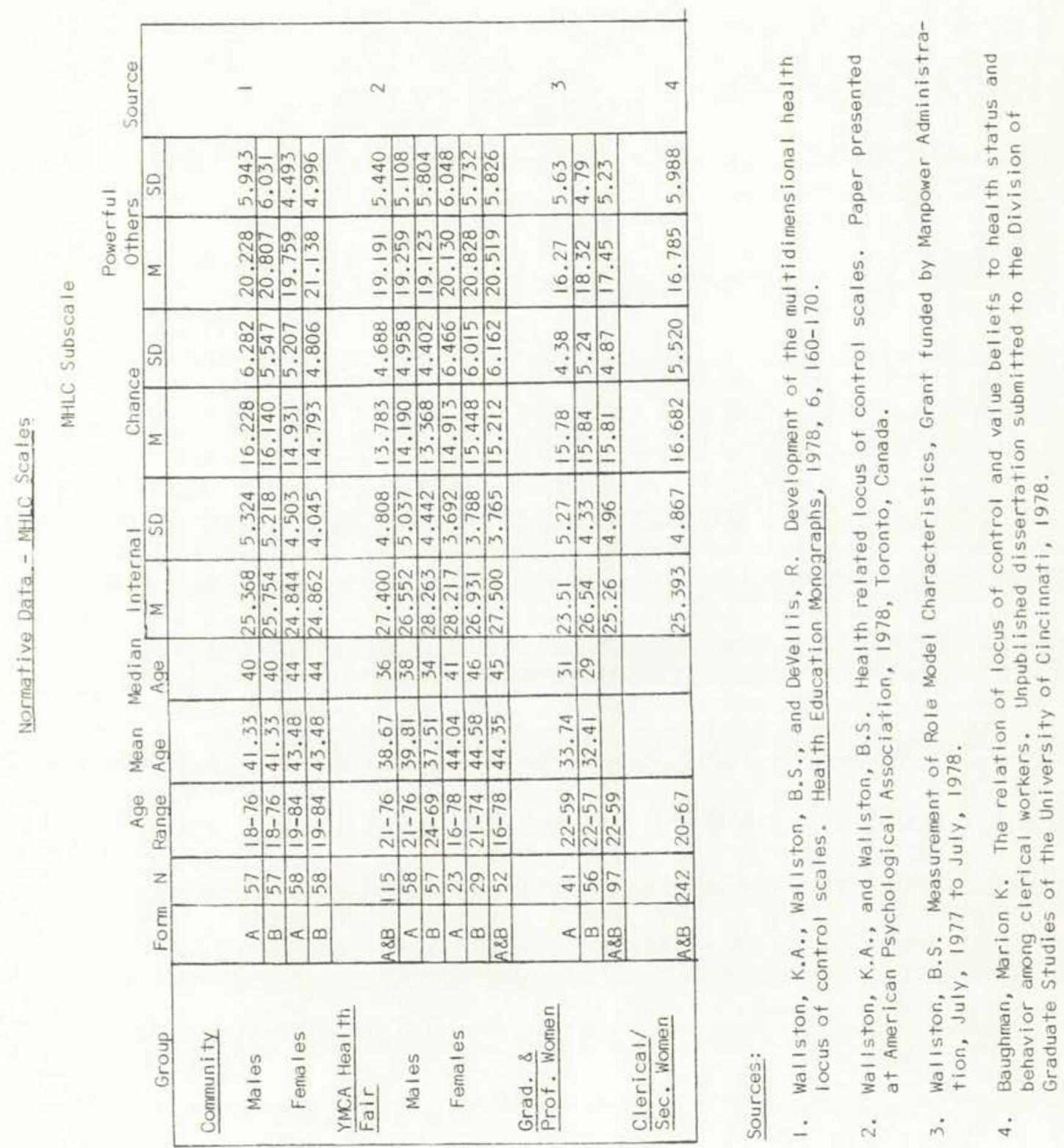

APPENDIX B 


\section{Demographic Data Collection Instrument}

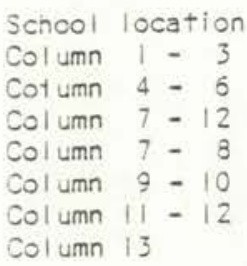

Col umn $24-25$

Column $26-27$

$$
\begin{array}{ll}
\text { Missing data } & =9 \\
\text { (Will not answer) } & =9
\end{array}
$$

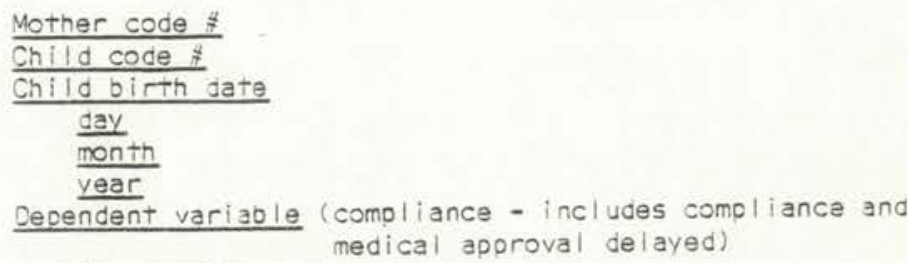


APPENDIX C 

Health Value Scale

Below you will find a list of ten values listed in alphabetical order. We would like you to arrange them in order of their importance to YOU, as guiding principles in YOUR life.

Study the list carefully and pick out the one value which is the most important for you. Write the number "I" in the space to the left of the most important value. Then pick out the value which is second most important to you. Write the number "2" in the space to the left. Then continue in the same manner for the remaining values until you have included all ranks from I to 10. Each value would have a different rank.

We realize that some people find it difficult to distinguish the importance of some of these values. Do the best that you can, but please rank all 10 of them. The end result should truly show how YOU really feel.

A COMFORTABLE LIFE (a prosperous I i fe)

AN EXCITING LIFE (a stimulating, active life)

A SENSE OF ACCOMPLISHMENT (lasting contribution) FREEDOM (independence) HAPPINESS (contendedness) HEALTH (physical and mental well-being) INNER HARMONY (freedom from inner conflict) PLEASURE (an enjoyable, leisurely life) SELF-RESPECT (self-esteem) SOCIAL RECOGNITION (respect, admiration) 
APPENDIX D 

Form A

\section{Multidimensional Health Locus of Contral}

This is a questionnaire designed to determine the way in which different people view certain important health-related issues. Each item is a belief statement with which you may agree or disagree. Beside each statement is a scale which ranges from strongly disagree ( 1 ) to strongly agree (6). For each item we would like you to circle the number that represents the extent to which you disagree or agree with the statement. The more strongly you agree with a statement, then the higher will be the number you circle. The more strongly you disagree with a statement, then the lower will be the number you circle. Please make sure that you answer every item and that you circle only one number per item. This is a measure of your personal beliefs; obviously, there are no right or wrong answers.

Please answer these items carefully, but do not spend too much time on any one item. As much as you can, try to respond to each item independently. When making your choice, do not be influenced by your previous choices. It is important that you respond according to your actual beliefs and not according to how you feel you should believe or how you think we want you to believe.

1. If I get sick, it is my own behavior

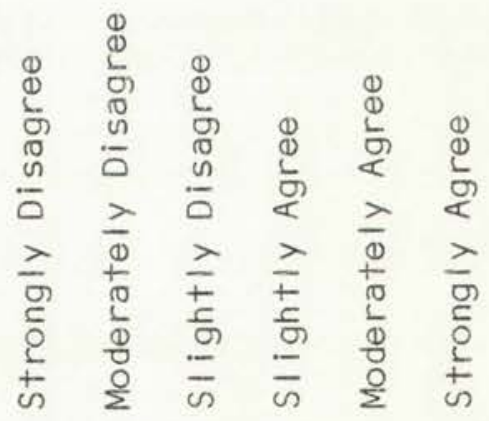
which determines how soon I get well again.

2. No matter what I do, if I am going to get sick, I will get sick.

3. Having regular contact with my physician is the best way for me to avoid ill ness.

4. Most things that affect my health happen to me by accident.

$\begin{array}{lllll}2 & 3 & 4 & 5 & 6 \\ 2 & 3 & 4 & 5 & 6 \\ 2 & 3 & 4 & 5 & 6\end{array}$





\section{APPENDIX D (cont.)}

Form A (cont.)

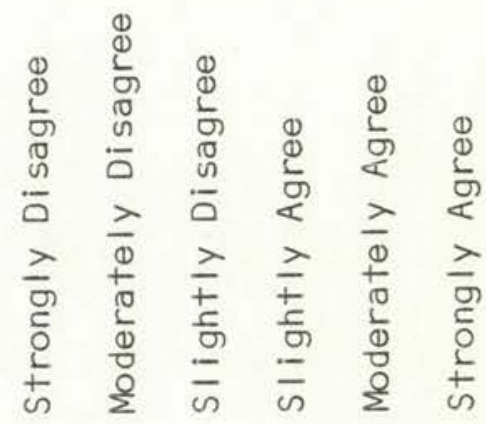

5. Whenever I don't feel well, I should consult a medically trained professional.

6. I am in control of my health.

$23 \quad 4 \quad 5 \quad 6$

7. My family has a lot to do with my becoming sick or staying healthy.

8. When ! get sick I am to blame.

9. Luck plays a big part in determining how soon I will recover from an illness.

10. Hea!th professionals control my health. $122 \quad 3 \quad 4 \quad 56$

11. My good health is largely a matter of good fortune.

$\begin{array}{lllll}2 & 3 & 4 & 5 & 6\end{array}$

$\begin{array}{lllll}2 & 3 & 4 & 5 & 6\end{array}$

The main thing which affects my health

is what I myself do.

$\begin{array}{lllll}2 & 3 & 4 & 5 & 6\end{array}$

13. If I take care of myself, I can avoid il Iness.

14. When I recover from an illness, it's

usually because other people (for

example, doctors, nurses, family, friends)

have been taking good care of me.

$\begin{array}{lllll}2 & 3 & 4 & 5 & 6\end{array}$

15. No matter what I do, I'm likely to get sick.

16. If it's meant to be, I will stay healthy. 

APPENDIX D (cont.)

Form A (cont.)

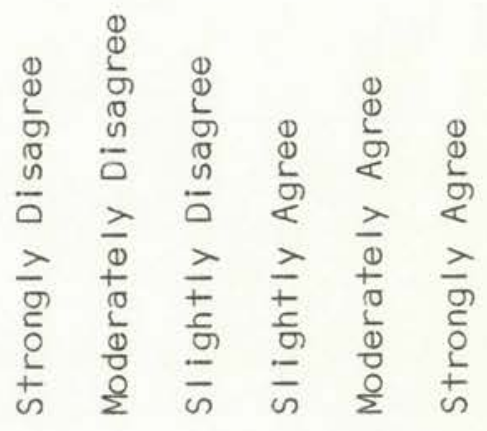

17. If I take the right actions, I can stay healthy.

123456

18. Regarding my health, I can only do what my doctor tells me to do.

$\begin{array}{lllll}2 & 3 & 4 & 5 & 6\end{array}$ 



\section{APPENDIX D (cont.) \\ Scoring Instructions}

\section{Health Locus of Control Scale}

The score on each subscale is the sum of the values circled for each item in that subscale.

Internal Items:

Chance 1tems:

Powerful Others 1tems:
$1,6,8,12,13,17$

$2,4,9,11,15,16$

$3,5,7,10,14,18$ 

APPENDIX E 


\section{APPENDIX E \\ Communicable Disease Perceived Vulnerability Scale}

People have certain at+itudes about communicable diseases.

Before you took your child for immunizations you probably had

certain feelings or attitudes about whether or not your child

was susceptible to certain childhood diseases. Which answer

comes closest to how you felt about your child catching one of

these diseases without providing the required immunizations.

What chance was there of your child getting each of these

diseases without the required immunization?

No Almost Some Almost

Chance No Chance Chance Certain Certain

Diphtheria

2

3

4

5

Pertussis

(Whooping

Cough)

Tetanus

1

2

3

4

5

Poliomyelitis

(Infantile

2

3

4

5

Paralysis)

Measles

(Hard)

1

2

3

4

5

Rubella

(German

1

2

3

4

5

Measles) 
APPENDIX F 
NEW MEXICO HEALTH AND ENVIRONMENT DEPARTMENT HEALTH SERVICES OIVISION

\section{IMMUNIZATION SCHEDULE}

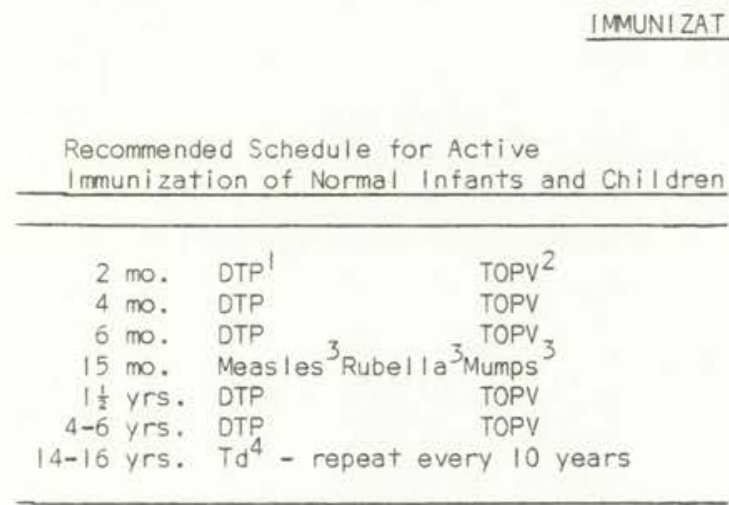

1) DTP - diptheria and tetanus toxoids combined with pertussis vaccine.

2) TOPV - trivalent oral poliovirus vaccine. This recommendation is suitable for breast-fed as well as bottle-fed infants.

3) May be given at 15 montins as measlesrubella or measles-mumps-rubella combined vaccine. Measles vaccine is not routinely given before 15 months of age. When rubella vaccine or mumps vaccine is provided in combination with measles vaccine, the combination vaccine should not be routinely given before 15 months of age.

Measles-rubel la combined vaccine should not be administered to anyone after the 12th birthday.

Rubella vaccine should not be administered to anyone after the 12 th birthday.

Measles vaccine should be administered to males through high school; measles vaccine should not be administered to females after the 12 th birthday.

Mumps vaccine is not required for entry into school at any level.
May, 1978

Primary Immunization for Children Not Immunized in Early Infancy

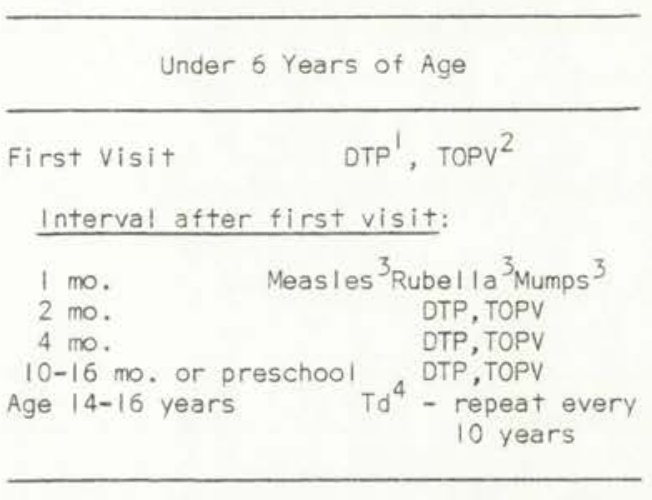

6 Years of Age and Over

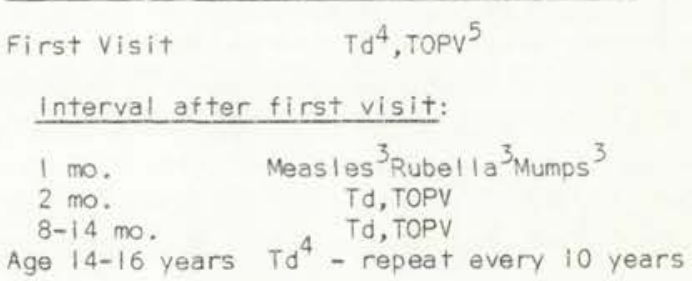

\section{(Notes, continued)}

Mumps vaccine is recommended to be given in combination with measles and rubella vaccine. However, mumps vaccine is also available for persons who have al ready received measles and rubella vaccination.

4) Td - combined tetanus and diptheria toxoids (adult type) for those more than 6 years of age, in contrast to diptheria and tetanus (TD) toxoids which contain a larger amount of diptheria antigen.

5) TOPV should not be administered to anyone after the 18th birthday. 
APPENDIX G 

Ann Beck, Director Head Start Program Office of Economic Opportunity

Dear Ann:

This letter is being written as a follow-up to our telephone conversation today concerning my doctoral study. As you know, I am a teacher of public health nursing at the University currently working on my doctorate in community health education.

The doctoral study I am designing will be based on interviews with mothers of children aged two to six years of age. The interview will involve asking some questions about the immunization status of the child plus taking an attitude scale about health. The purpose of the study is to learn more about health attitudes concerning immunization. Naturally, I nope that this study will contribute to a better understanding of immunization practices.

If you have space in your centers, I would arrange to meet mothers there for the interview which should take no longer than twenty minutes. I plan to schedule them every half hour so that I can serve as a resource person to the mother following the interview if they have questions to ask.

There is no risk involved and no deception in this study. The children, themselves, are not involved. Mothers would be asked to bring official records of immunization and no one would be identified by name in the study, only by demographic data.

It would be a pleasure and a privilege to work with the mothers in your program. Please contact me if you have any further questions. I would like to begin sometime in mid-March and complete the interviews before mid-May.

Thank you so much for your help in presenting this information to the Council. I am awaiting your reply.

\section{Sincerely yours,}

$$
\text { /S/ }
$$

Estelle Rosenblum, R.N., M.A.

Associate Professor

College of Nursing

University of New Mexico

Doctoral Student in Health Education

telephone numbers: office: $277-3847$

home: $265-1483$ address

College of Nursing

U. of New Mexico

Alb., N.M. 87131 

APPENDIX $\mathrm{H}$ 

Dear Mrs. Sanchez:

I am a teacher of nursing working on a doctorate at the University of New Mexico. As part of my study I will be talking to mothers about their attitudes toward immunization and health.

I would like to invite you to take part in this study. Would you please bring your childrens' immunization records with you when you come to the interview. The times for interviews are posted on the bulletin board in the Center, but I would be happy to come visit you at home if you can't find a time to come to the Center.

The interview will take about 20 minutes. Your help is really appreciated. Please select a time when you can come for this short interview.

\section{Sincerely yours,}

|S/

Estelle Rosenblum, R.N.

\section{Consent Form}

I understand the purpose and nature of the study on immunization attitudes. I agree to participate in the interviews for this study.

Signed:

(Name of mother)

Faculty Advisor:

Elaine Stone, PhD

Coordinator, Health Education

University of New Mexico

Telephone No. 277-2138
Estelle Rosenblum, R.N.

College of Nursing University of New Mexico

Telephone No. 277-4221

or $277-3847$ 

APPENDIX : 


\section{APPENDIX I \\ Reliability Data \\ The Perceived Vulnerability Scale}

Reliability

$\begin{array}{ll}\text { Pearson Correlation Coefficients } & \underline{r} \\ \text { Diphtheria } & .68 \\ \text { Pertussis } & .68 \\ \text { Tetanus } & .79 \\ \text { Polio } & .54 \\ \text { Measles } & .49 \\ \text { Rubella } & .31\end{array}$

Total Scale (all six diseases combined) ,71 
APPENDIX J 
APPENDIX J

Pilot Study Subjects

Demographic Data

$$
N=19
$$

\section{Ethnicity}

Ang 10

Hispano

Other

Total

Number

8

10

1

19

8

8

1

2

Total

19

\section{Religion}

\section{Percent}

42.1

52.6

5.3

$100 \%$
Catholic

Protestant Jewish

other

\section{Age}

$$
\begin{aligned}
& 24 \\
& 25 \\
& 26 \\
& 27 \\
& 28 \\
& 30 \\
& 32 \\
& 38 \\
& 45
\end{aligned}
$$

42.1

42.1

5.3

10.5

$100 \%$
3

2

3

2

3

3

1

1

1

Median $=27.25$
15.8

10.5

15.8

10.5

15.8

15.8

5.3

5.3

5.3

$\bar{x}=28.58$

Mode $=24$ 

APPENDIX J (cont.)

Income

Less than $\$ 10,000$

$\$ 10,000-19,999$

More than $\$ 20,000$

Total
Number

5

12

2

19

\section{Education}

Less than High School

High School (9-12)

High School Graduate

Some Coll lege

Col lege Graduate

Graduate Education

\section{Percent}

26.3

63.2

10.5

$100 \%$

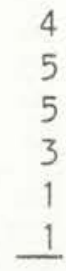

19 
APPENDIX K 



\section{APPENDIX K \\ Total Study \\ Demographic Data}

\section{Educational Level}

Less than High School

Grades 9-12

High School Graduate

Some Coll lege

College Graduate

Total
Number

17

31

24

21

2

95

77

1

1

95
2

9

5

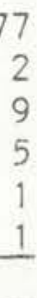

5

\section{Percent (Adjusted)}

17.9

32.6

22.1

22.1

2.1

$100 \%$ indian

Oriental

other

Total
81.1
2.1
9.5
5.3
1.1
1.1
$100 \%$

Age
Range
Mean
19-67 years
Median
28.91
27.69
Mode
28
Standard Deviation
7.25 
REFERENCES 


\section{REFERENCES}

Antonovski, A., \& Hartman, H. Delay in the detection of cancer: A review of literature. Health Education Monographs, 1974, 2 , $98-128$.

Antonovski, A., \& Katz, R. The model dental patient: An empirical study of preventive health behavior. Social Science Medicine, $1970, \underline{4}, 367-380$.

Anthony, N., Reed, N., Leff, A. M., Huffer, J., \& Stephens, B. Immunization: public law. American Journal of Public Health, August, 1977, 67(8), 763-764.

Archer, S. E., \& Fleshman, R. Community health nursing. Belmont, California: Duxbury Press, Wadsworth Publishing Co., 1975.

Ary, D., \& Jacobs, L. C. Introduction to statistics: purposes and procedures. New York: Holt, Rinehart and Winston, 1976.

Baron, R. M., \& Ross, A. W. Predicting success in weight reduction as a function of locus of control: A unidimensional and multidimensional approach. Journal of Consulting and Clinical Psychology, 1974, 30(2), 285-292.

Bassilli, W. R., \& Stewart, G. T. Epidemological evaluation of immunization and other factors in the control of whooping cough. The Lancet, February 28, 1976, 471-473.

Battle, E., \& Rotter, J. B. Children's feelings of personal control as related to social class and ethnic groups. Journal of Personality, 1963, 31, 482-490.

Bean, J., Burmeister, L., Paule, C., \& Isacson, P. A comparison of national infection and immunization estimates for measles and rubella. American Journal of Public Health, 1978, 68(12), $1214-1215$.

Becker, M. H. (Ed.). The health belief model and personal health behavior. Thorofare: Charles B. Slack, Inc., 1974.

Becker, M. H., Drachman, R. H., \& Kirscht, J. P. A new approach to explaining sick-role behavior in low income populations. American Journal of Public Health, 1974, 64, 205-216. 
Becker, M. H., \& Green, L. W. A family approach to compliance with medical treatment. Paper presented to the American Association for the Advancement of Science, New York, January $27,1975$.

Becker, M. H., Drachman, R. H., \& Kirscht, J. P. Predicting mothers' compliance with pediatric medical regimens. Journal of Pediatrics, 1972, 81, 843-853.

Brodie, J. N. The relationship between general fearfulness, locus of control and social activity among retirees. In F. Downs and M. Newman (Eds.), A Sourcebook of Nursing Research. Philadelphia: F. A. Davis, Co., 1977, 109-117.

Bugental, D. B., Whalen, D. K., \& Henken, B. Causal attributions of hyperactive children and motivational assumptions of two behavior change approaches: Evidence for an interactionist position. Child Development, 1977, 48, 874-884.

Bullough, B. Poverty, ethnic identity and preventive health care. American Journal of Public Health, 1972, 13, 353-354.

Bussey, A., \& Hoimes, B. S. Immunization ieveis - Need they ail decline? The Lancet, November 5, 1977, 969-971.

Campbell, J. D. Attribution of illness: Another double standard. Journal of Health and Social Behavior, 1975, 16, 114-119.

Castetter, W. B., \& Heisler, T. Developing and defending a dissertation proposal. Center for Field Studies, Graduate School of Education, the University of Pennsylvania, Philadelphia, Pennsylvania, 1977.

Center for Disease Control. Measles surveillance, 1972 summary. Department of Health, Education and Welfare Publication No. (CDC) 74-8253. U. S. Government Printing Office, 1973.

Center for Disease Control. Morbidity and mortality report, Recommendations of the Public Health Service Advisory Committee on Immunization Practices: Diphtheria and Tetanus Toxoids and Pertussis Vaccine, 1977, 26(49).

Center for Disease Control. Morbidity and mortality report, $1978,27(16), 451-452$.

Center for Disease Control. Morbidity and mortal ity report, Poliomyelitis - Netherlands, 1978, 27(26), 222-223. 
.
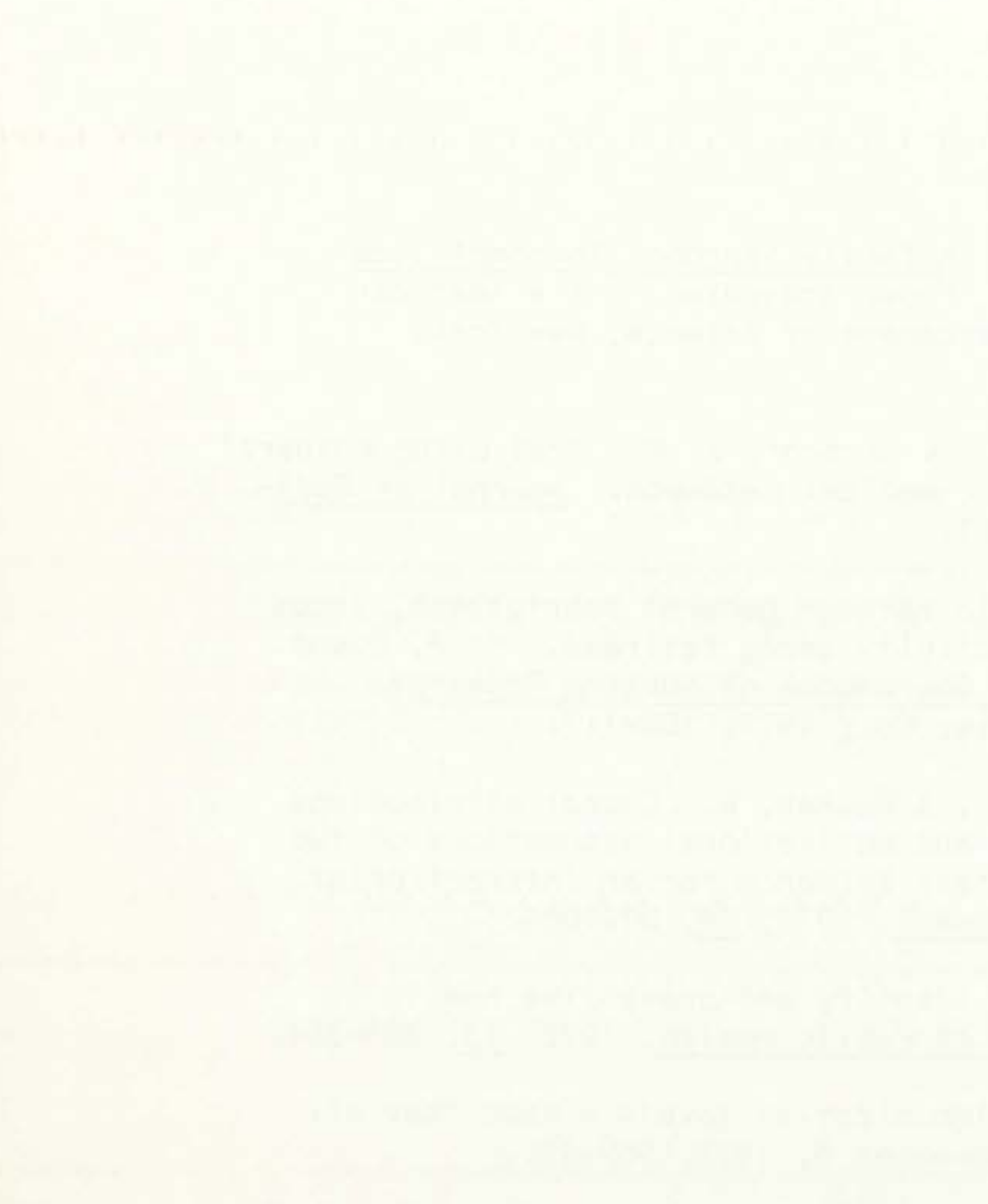
Center for Disease Control, Morbidity and mortality report, Measles - United States, 1978, 27(28), 235-236.

Center for Disease Control, Morbidity and mortal ity report, Measles - North Carolina, 1978, 27(28), 244-245.

Center for Disease Control, Morbidity and mortal ity report, Measles - Indiana, 1978, 27(39), 369-370.

Center for Disease Control, Morbidity and mortal ity report, Mumps - United States, 1978, 27(40), 379-380.

Center for Disease Control, Morbidity and mortal ity report, Goal to el iminate measles from the United States, $1978,27(41), 391-392$.

Center for Disease Control, Morbidity and mortal ity report, Measles prevention, 1978, 27(44), 427-428.

Center for Disease Control, Morbidity and mortality report, DTP vaccine reactions - Montana, 1978, 27(47), 471-472.

Center for Disease Control, Morbidity and mortal ity report, Rubella and congenital rubella, 1978, 27(49), 495-496.

Center for Disease Control, Morbidity and mortality report, Measles - Texas, 1978, 27(49), 489-490.

Center for Disease Control, Morbidity and mortality report, Measles - Oregon, 1978, 27(51), 519-520.

Center for Disease Control, Morbidity and mortality report, Measles - Utah, 1978, 28(2), 108-109.

Clausen, J. A., \& Seidenfeld, M. A. Parent attitudes toward participation of their children in polio vaccine trials. American Journal of Public Health, 1954, 44, 1526-1536.

Coburn, D., \& Pope, C. Socio-economic status and preventive health behavior. Journal of Health and Social Behavior, 1974, 15, 67-77.

Dabbs, J. M., \& Kirscht, J. P. Internal control and the taking of influenza shots. Psychologica! Reports, 1971, 28, 959-962.

Dodge, W. F. Patterns of maternal desires for child health care. American Journal of Public Health, 1970, 60, $|42|-\mid 429$. 
Dowling, W. F. Fighting infection: Conquest of the twentieth century. Cambridge: A Commonwealth Fund Book, Harvard University Press, 1977.

Downs, F., \& Newman, M. A sourcebook of nursing research. Philadelphia: F. A. Davis, Co., 1977.

Durkheim, E. Essays on sociology and philosophy. New York: Harper and Row, 1960.

Enelow, A. J. Group influences on health behavior: A social learning perspective. In J. A. Cullen (Ed.), Cancer: The behavioral dimensions. New York: Raven Press, 1976.

Fox, D. Research in nursing. Third Edition. New York: Appleton-Century-Crofts, 1976.

Fox, J., Hall, C., \& Elveback, L. Epidemiology. London: The MacMillan Co., 1970.

Girdano, D. A., \& Girdano, D. D. Performance-based evaluation. Health Education, March-April, 1977, $\underline{8}(2), 13-15$.

Glasser, M. A. A study of the public's acceptance of the Salk vaccine program. American Journal of Public Health, 1958, $48,|4|-146$.

Gochman, D. S. Children's perceptions of vulnerability to illness and accidents: A replication, extension and refinement. Health Services Mental Health Association Health Reports, 1971, 86, 247-252. (a)

Gochman, D. S. Some correlates of children's health beliefs and potential health behavior. Journal of Health and Social Behavior, $1971,12,148-154$. (b)

Gochman, D. S. The organizing role of motivation in health beliefs and intentions. Journal of Health and Social Behavior, 1972, 13, 285-293.

Gordis, L., Markowitz, M., \& Lilienfeld, A. M. The inaccuracy in using interviews to estimate patient reliability in taking medications at home. Medical Care. 1969, 7, 49-54.

Gray, R. The effects of social class and friend's expectations on oral polio vaccination participation. American Journal of Public Health, 1966, 56, 2028-2032. 

Green, L. W. Manual for scoring socio-economic status for research on health behavior. Public Health Reports, September, 1970, $85(9), 815-827$. (a)

Green, L. W. Status identity and preventive health behavior. Pacific Health Education Reports, 1970, 1, Berkeley: University of California. (b)

Green, L. W. Suggested designs for evaluation of patient education programs. Richards, R., \& Kramer, H., Patient Education, Spring, 1974 (Monograph $\underline{2}(1)$ ).

Gunn, W. (Ed.). Public attitude toward immunization: August, 1977 and February, 1978, I, II \& III, Bureau of Health Education, Center for Disease Control, Atlanta, 1978. (a)

Gunn, W. Racial differences in attitudes regarding childhood immunization. Bureau of Health Education, Center for Disease Control, Atlanta, 1978. (b)

Guthrie, N. Immunization status of two year old infants in Memphis and Shelby County, Tennessee. Public Health Reports, $1963,78,443-447$.

Hanlon, J. J. Public health: Administration and practice. Sixth Edition, St. Louis: C. V. Mosby Co., 1974.

Hail, J. E., \& Weaver, B. Distributive nursing practice: A systems approach to community health. Philadelphia: J. B. Lippincott, 1977.

Hayden, G. F., Preblud, S. R., Orenstein, W. A., \& Conrad, J. L. Current status of mumps and mumps vaccine in the United States. Pediatrics, December 1978, 62(6), 965-969.

Hochbaum, G. M. Public participation in medical screening programs: A socio-psychological study. Publication No. 572, Washington, D.C.: U. S. Department of Health, Education and Welfare, Public Health Service, 1958.

Hollingshead, A. B., \& Redlich, C. C. Social stratification and psychiatric disorders. American Social Review, April, 1953, $18,163-169$.

Hsieh, T. T., Shybut, J., \& Lotsof, E. J. Internal versus external control and ethnic group membership. Journal of Consulting and Clinical Psychology, 1969, 33, 122-124. 
Huck, S., Cormier, W. H., \& Bounds, W. Reading statistics and research. New York: Harper and Row, 1974.

Insel I, P. M., \& Roth, W. T. Health in a changing society. Mayfield Publishing Co., 1976.

Johnson, M. C. A review of research methods in education.

Chicago: Rand McNally College Publishing Co., 1977.

Kaplan, G., \& Cowles, A. Health locus of control and health value in the prediction of smoking reduction. Health Education Monographs, 1978, 6, 129-137.

Kasl, S. V., \& Cobb, S. Health behavior, illness behavior and sick-role behavior. Archives of Environmental Health, February, 1966, 12, 246-266. (a)

Kasl, S. V., \& Cobb, S. Health behavior, illness behavior and sick-role behavior. Archives of Environmental Health, April, 1966, 12, 534-541.

Kegeles, S. S. Kirscht, J. P., Haefner, D. P, \& Rosenstock, I. M. Survey of beliefs about cancer detection. Public Health Reports, September 1967, 80, 815-824.

Keller, A. B., Simms, J. H., \& Henry, W. E. Psychological sources of resistance to family planning. Merrill-Palmer Quarterly, $1970,16,286-302$.

Kirk, R. E. Experimental design: Procedures for the behavioral sciences. Belmont, California: Wadsworth Publishing Co., 1968.

Kirscht, J. P. Perceptions of control and health beliefs. Canadian Journal of Behavioral Science, 1972, 4, 225-237.

Kirscht, J.P., Haefner, D. P., Kegeles, S., \& Rosenstock, I. M. A national study of health beliefs. Journal of Health and Human Behavior, Winter, 1966, I, 248-254.

Knutson, A. L. The individual, society and health behavior. New York: Russell Sage Foundation, 1974.

LeavelI, H. R., \& Clark, E. G. Preventive medicine. Second Edition, New York: McGraw-Hill, 1958.

Lefcourt, H. M. Locus of control: Current trends in theory and research. New York: John Wiley and Sons, 1976. 

Lewis, F. M., Moriskey, D. E., \& Flynn, B. S. A test construct validity of health locus of control: Effects of selfreported compliance for hypertensive patients. Health Education Monographs, Spring, 1978, SOPHE, 16(1), 101-105.

Lundy, J. R. Some personality correlates of contraceptive use among unmarried female college students. Journal of Personal ity, 1972, 80, 9-14.

MacDonald, A. P., Jr. Internal-external locus of control and the practice of birth control. Psychological Reports, 1970, 27, 206-209.

Maiman, L., Becker, M., \& Kirscht, J. P. Scales for measuring health belief model dimensions: A test for predictive value, internal consistency, and relationships among beliefs. Health Education Monographs, 1977, $\underline{5}(3), 215-230$.

Mann, J., \& Crowe, J. Interview, personal communication, Santa Fe, New Mexico Health and Environment Department, November 9, 1978.

Manno, B., \& Marston, A. R. Weight reduction as a function of negative covert reinforcement (sensitization) versus positive cover reinforcement. Behavior Research Therapy, 1972, 10, 201207.

Markland, R. E., Durand, D. E., \& Douglas, E. An investigation of socio-psychological factors affecting infant immunization. American Journal of Public Health, February 1976, $66(2)$, $168-170$.

Marston, M. Compliance with medical regimens: A review of the I iterature. Nursing Research, 1970, 19, 312-323.

Mckinley, J. Some approaches and problems in the study of the use of services: An overview. Journal of Health and Social Behavior, June 1972, XIII.

Mechanic, D. The influence of mothers on their children's health attitudes and behavior. Pediatrics, 1964, 33, 444-545.

Milio, N. A framework for prevention changing health-damaging to health-generating life patterns. American Journal of Public Health, May 1976, 66(5), 435-439. 
Moody, E., \& Jaco, E. G. Social class, social integration and the use of preventive health services. In Jaco, E. G. (Ed.), Patients, physicians and ill ness. New York: Free Press, 1972, 250-260.

Morris, N. Alienation as a deterrent to well-child supervision. American Journal of Public Health, 1968, LV, 1874-1882.

New Mexico Procedural Manual for Enforcement of School Immunization Law. New Mexico Statute Annotated, 1953, 12-3-4.1 through $12-3-4.6$.

Nicholas, A. Immunization: Public health programming through law enforcement. American Journal of Public Health, 1977, 67 (8), 763-764.

Nie, N. H., Hull, C. H., Jenkins, J. G., Steinbrenner, K., \& Bent, D. H. Statistical package for the social sciences. New York: McGraw-Hill, Inc., 1975.

Northern, J., \& Downs, M. Hearing in children. Baltimore: Williams and wilkins, 1976.

Oberteuffer, D., Harrelson, D. A., \& Pollock, M. B. School health education, Fifth Edition. New York: Harper and Row, 1972.

Opinion Research Corporation, Public attitudes toward immunization, I \& III, Atlanta: U. S. Government, Department of Health, Education and Welfare, Public Health Service, Center for Disease Control, Bureau of Health Education, HEW \#200-77-0723, 1978.

Parcel, G. S., \& Meyer, M. P. Development of an instrument to measure children's locus of control. Health Education Monographs, 1978, $\underline{6}(1), 149-159$.

Pearman, W. A. Participation in flu immunization projects: What can we expect in the future? American Journal of Public Health, 1978, 68(7), 674-675.

Phares, E. J. Expectancy changes in skill and chance situations. Journal of Abnormal and Social Psychology, 1957, 54, 339342.

Phares, E. J. Locus of control in personality. Morristown: General Learning Press, 1976. 
Read, D. New directions in health education. Report of the Committee on the Control of Infectious Diseases, 1977, Evanston, Illinois: American Academy of Pediatrics.

Report of the President's Committee on Health Education. New York: U. S. Department of Health, Education and Welfare, Health Services and Mental Health Administration, 1971.

Rosenblum, E. H. Fundamentals of hearing for health professionals. Boston: Lit+le-Brown \& Co., 1979.

Rosenstock, 1. The health belief model and preventive health behavior. Health Education Monographs, 1974, 2(4), 354-386.

Rosenstock, 1., Derryberry, I. M., \& Carriger, B. K. Why people fail to seek polio immunization. Public Health Reports, February 1959, 74, 98-103.

Roter, D. Patient participation in the patient provider interaction: The effects of patient question asking on the quality of interaction, satisfaction and compliance. Health Education Monographs, 1977, 5(4), 281-315.

Rotter, J. B. Generalized expectancies for internal versus external control of reinforcement. Psychological Monograph, $1966,80(1), 609$.

Rotter, J. B. Social learning and clinical psychology. New York: Prentice-HalI, Inc., 1954.

Rotter, J. B. Some problems and misconceptions related to the construct of internal versus external control of reinforcement. Journal of Consulting and Clinical Psychology, 1975, 43, 56-57.

Rotter, J. B., Chance, J. E., \& Phares, E. J. Application of a social learning theory of personality. New York: Holt, Rinehart and Winston, 1972.

Russell, R. At+itudes and other factors of behavior. Washington, D.C.: National Education Association, 1975.

Saltzer, E. B. Locus of control and the intention to lose weight. Health Education Monographs, Spring 1978, 6(2), 118-127.

Seeman, M. On the meaning of alienation. American Social Review, 1959, XXIV (24), 783-787. 
Shelton, J. D., Jacobson, J. E., Orenstein, W. A., Schultz, K. F., \& Donnell, H. D., Jr. Measles vaccine efficacy: Influence of age at vaccination versus duration of time since vaccination. Pediatrics, 1978, 62(6), 961-965.

Sherman, S. J. Internal-external control and its relationship to attitude change under different social influence techniques. Journal of Personality and Social Psychology, 1973, 26 (1), 23-29.

Shireffs, J. H. The relevance of health education to health activation and self-care. Journal of School Health, 1978, 48, 419422.

Smolensky, J. Principles of community health. Fourth Edition. New York: J. B. Saunders, 1977.

Spradley, B. W. Contemporary community nursing. Boston: Little, Brown \& Co., 1975.

Steele, J. L., \& McBroom, W. H. Conceptual and empirical dimensions of health behavior. Journal of Health and Social Behavior, 1972, 13, 153-165.

Stone, E. The effects of a health education curriculum on locus of control, perceived vulnerability and health attitudes of fifth graders. Unpublished doctoral dissertation, University of New Mexico, 1976.

Strickland, B. Locus of control: Where have we been and where are we going? Journal of Consulting and Clinical Psychology, $1976, \underline{4}, 580-585$.

Stuart, A. Basic ideas of scientific sampling. No. 4 of Griffins Statistical Monographs and Courses, New York: Hafner Publishing Co., 1968.

Suchman, E. A. Preventive health behavior: A model for research. Pittsburgh: University of Pittsburgh, 1967.

Suchman, E. A. Social patterns of illness and medical care. Journal of Health and Human Behavior, 1965, 6, 7-16.

Thornhill, J. A., \& Youngman, M. B. A computerized and categorized bibliography on locus of control. Psychological Reports, $1975,36,505-506$. 
Throop, W. F., McDonald, A. J., \& Youngman, M. B. A bibliography on locus of control. Psychological Reports, 1971, 28, 175-190.

Treece, E. W., \& Treece, J. W., Jr. Elements of research in nursing. St. Louis: The C. V. Mosby Co., 1973.

Van Dalen, D. B. Understanding educational research: An introduction. New York: McGraw-Hill, 1973.

Vernon, T. M., Conner, J. S., Brent, S., Lampe, J. M., \& Doster, M. E. An evaluation of three techniques for improving immunization levels in elementary schools. American Journal of Public Health, 1976, 66, 450-460.

Vincent, P. Factors influencing patient noncompliance: A theoretical approach. Nursing Research, 1971, 20, 509-516.

Wallston, B. S., Wallston, K. A., Kaplan, G. D., \& Maides, S. A. Development and validation of the health locus of control (HLC) scale. Journal of Consulting and Clinical Psychology, 1976, $\underline{44}(4), 580-585$.

Wallston, B. A., \& Wallston, K. A. Locus of control and heaith: A review of the literature. Health Education Monographs, 1978, 6(2), $107-111$. (a)

Wallston, B. S., Wallston, K. A., \& DeVellis, R. Development of the multidimensional heaith locus of control (MHLC) scales. Health Education Monographs, 1978, 6(2), $161-169$. (b)

Wallston, B. S., \& Wallston, K. A. Health related locus of control scales. Goal specific locus of control scales - a new step in 1-E research, American Psychological Association Symposium, Toronto, Canada, September I, 1978. (c)

Wallston, B. S. Vanderbilt University, December 9, 1978. Telephone conversation and correspondence. (d)

Wan, T. T., \& Gray, L. C. Differential access to preventive services for young children in low-income urban areas. Journal of Health and Social Behavior, 1978, 19, 312-324.

Wang, V. L., Reiter, H., Whaples, C., \& Lentz, H. An approach to consumer patient activation in health maintenance. Public Health Reports, 1975, 90, 449-454.

Wittee, J. J. Recent advances in public health immunization. American Journal of Public Health, 1974, 64, 939-944. 


\section{CURRICULUM VITAE}

\section{ESTELLE HELENE ROSENBLUM}

BORN: February 8, 1933 at Davenport, lowa

EDUCATION: 1956 B.S. in Nursing, Wayne University

1971 M.A. in Speech (Audiology), University of New Mexico

1979 Ph.D. University of New Mexico

PROFESSIONAL LICENSURE: Registered Nurse

1956 Michigan

1960 Colorado

1962 New Mexico

HONORS: $\quad 1977$ Eta Sigma Gamma Health Education Honor Society

1977 Phi Kappa Phi Scholastic Honor Society

1955 Sigma Theta Tau Honor Society of Nursing

1969-1971 Office of Education Graduate Fellowship

1979-1980 Who's Who of American Women

1978 International Who's Who of Women in Education

PROFESSIONAL EXPERIENCE:

1956 Psychiatric Head Nurse

Northville State Hospital, Michigan

1957-1960 Poliomyelitis Rehabilitation Nurse

Sister Kenny Polio Hospital, Michigan

1960-1962 Public Health Nurse

Englewood County Health Department, Colorado

1963-1965 Nurse Supervisor

Bernalillo County Indian Hospital, New Mexico

1967-1969 School Nurse

Albuquerque Public Schools, New Mexico

1969-1971 Graduate Student and Clinician

Speech and Hearing Center, University of New Mexico

1972-1974 Instructor

College of Nursing, University of New Mexico

1974-1978 Assistant Professor

College of Nursing, University of New Mexico

1978-present Associate Professor

College of Nursing, University of New Mexico 
PUBLICATIONS:

Rosenblum, E. H., \& Jones, A. Disaster nursing. Nursing 176 , $1976,72-73$.

Rosenblum, E. H. Fundamentals of hearing for health professionals. Boston: Lit+le-Brown and Co., 1979.

Rosenblum, E. H., \& Sands, P. Self-care: Report on a research project in a health maintenance organization in CHOL approach for community health education. Bureau of Health Education, DHEW, 1979. 





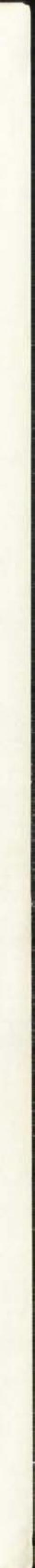


